\title{
En búsqueda de una doctrina contrasubversiva propia. Las tesis de ascenso de los oficiales guatemaltecos, 1975-1985*
}

\author{
LAURA YANINA SALA**
}

Artículo recibido: 11 de noviembre de 2018

Artículo aprobado: 11 de julio de 2019

Doi: https://doi.org/10.12804/revistas.urosario.edu.co/desafios/a.7388

Para citar este artículo: Sala, L.Y. (2020). En búsqueda de una doctrina contrasubversiva propia. Las tesis de ascenso de los oficiales guatemaltecos, 1975-1985. Desafíos, 32(2), 1-47. Doi: https://doi.org/10.12804/revistas.urosario.edu.co/desafios/a.7388

\section{Resumen}

Este articulo propone matizar la perspectiva dominante respecto de la Doctrina de Seguridad Nacional (DSN) en Guatemala según la cual el Ejército aparece como un mero apéndice receptor de ideas desde Estados Unidos. Parte del supuesto de que las doctrinas militares de los años setenta y ochenta han sido producto de un complejo proceso de elaboración que, si bien tuvo a Estados Unidos como actor clave, involucró aspectos socio-históricos particulares y actores locales, regionales e internacionales. A partir del análisis de Tesis de Ascenso de oficiales del Ejército de Guatemala

\footnotetext{
* Este texto se inscribe en mis avances de investigación doctoral en Ciencias Sociales en la Universidad de Buenos Aires (UBA) (Argentina). Agradezco a Manolo Vela por sus valiosos comentarios.

** Consejo Nacional de Investigaciones Científicas y Técnicas con sede en el Instituto de Estudios de América Latina y El Caribe, Universidad de Buenos Aires (Argentina). Docente regular de la Universidad Nacional de José C. Paz (Argentina). Correo electrónico: laurasala@hotmail.com.ar. ORCID: https://orcid.org/0000-0003-2463-0931
} 


\title{
2 I LAURA Yanina SALA
}

mostramos que, en el periodo 1975-1985, se desató una preocupación por parte del Alto Mando, y de la oficialidad en general, por establecer una doctrina propia que guiara el accionar militar para enfrentar a "la subversión". En segundo lugar, exponemos las diferencias de enfoques prevalecientes entre los oficiales. Finalmente, identificamos las referencias bibliográficas que nutrieron la elaboración doctrinaria local en la que se destacan textos de militares sudamericanos y taiwaneses.

Palabras clave: Guatemala; fuerzas militares; contrainsurgencia; doctrina; cultura militar.

\section{In search of an Own Counter-Subversive Doctrine: The Promotion Thesis of Guatemalan Officers, 1975-1985}

\begin{abstract}
This article proposes to qualify the dominant perspective regarding the National Security Doctrine (NDS) in Guatemala, according to which the Army appears as a mere recipient of ideas from the US. It assumes that the military doctrines of the seventies and eighties have been the product of a complex elaboration process that, even though the US were a key actor, involved particular socio-historical aspects and local, regional and international actors. Based on an analysis of the Guatemalan Army Officers Promotion Thesis we show that, during the period 1975-1985, concerns were raised by the High Command and the officers in order to establish their own doctrine to guide military actions against "subversion". Second, we expose the differences in prevailing approaches among officers. Then, we identify the bibliographical references that nurtured the local doctrinal elaboration in which texts from South American and Taiwanese military stand out.
\end{abstract}

Keywords: Guatemala; military forces; counterinsurgency; doctrine; military culture. 


\title{
Em busca de uma doutrina contra-subversiva própria. As teses de ascenso dos oficiais guatemaltecos, 1975-1985
}

\begin{abstract}
Resumo
Este artigo propõe matizar a perspectiva dominante respeito à Doutrina de Segurança Nacional (DNS) a Guatemala segundo a qual o Exército aparece como um mero a apêndice receptor de ideias desde os EUA. Parte do suposto de que as doutrinas militares dos anos setenta e oitenta têm sido produto de um complexo processo de elaboração que, embora teve aos Estados Unidos como ator chave, envolveu aspetos socio-históricos particulares e atores locais, regionais e internacionais. A partir da análise de Teses de Ascenso de oficiais do Exército da Guatemala mostramos que, no periodo 1975-1985, se desatou uma preocupação por parte do Alto Comando e da oficialidade em geral, por estabelecer uma doutrina própria que guie o acionar militar para enfrentar "a subversão". Em segundo lugar, expomos as diferenças de enfoques prevalecentes entre os oficiais. Depois, identificamos as referências bibliográficas que nutriram a elaboração doutrinária local na que se destacam textos de militares sul-americanos e taiwaneses.
\end{abstract}

Palavras-chave: Guatemala; forças militares; contrainsurgência; doutrina; cultura militar.

\section{Introducción}

Existe un amplio consenso entre las ciencias sociales y los estudiosos de la historia reciente de la región latinoamericana respecto a que los gobiernos y dictaduras militares y los procesos de represión estatal de los años setenta y ochenta tuvieron como fundamento ideológico a la Doctrina de Seguridad Nacional (DSN) (Comblin, 1979; Leal Buitrago, 2003; Maira, 1990; Methol Ferré, 1979; Nina, 1979; Tapia Valdés, 1980; Velásquez Rivera, 2002). No hay acuerdo general cuando se trata de desmenuzar la DSN en sus componentes y asignarles una jerarquía en relación con su procedencia (Buchrucker, 1994). Sin embargo, una de las miradas más difundidas y aceptadas en torno a la DSN es la que sitúa su origen en Estados Unidos, desde donde fue exportada a los ejércitos latinoamericanos a través del asesoramiento militar, cursos 


\section{4 / Laura Yanina Sala}

y formación de militares (Barros \& Coelho, 1981; Gill, 2004; López, 1989; Shirley, 1997). Para el caso centroamericano, esta explicación centrada en Estados Unidos tiene aún más asidero. Al respecto, Francisco Leal Buitrago (2002) señala que, en América Central, más que un desarrollo de la DSN, se adoptaron varios de los principios contenidos en la concepción norteamericana del "Estado de seguridad". Si bien Ernesto López planteó tempranamente que no se puede pensar en los ejércitos latinoamericanos como meros apéndices de Estados Unidos, sí consideró a las sociedades centroamericanas una excepción a razón de su menor nivel de desarrollo. Allí, sostuvo López, es inocultable la gran influencia que Estados Unidos ejerce sobre sus ejércitos (1987, p. 14).

Esta mirada respecto de la DSN en Centroamérica deja abiertos varios interrogantes históricos y epistemológicos respecto a la construcción doctrinaria de las fuerzas armadas en países donde los conflictos internos fueron los más significativos del continente en el período, y que alcanzaron, en el caso de Guatemala, el genocidio. ¿Los ejércitos adoptaron sin reparos una doctrina proveniente de Estados Unidos? ¿Cómo la incorporaron a sus prácticas y pensamientos? ¿Se imbricó con ideas propias? ¿Qué tipo de intereses internos a las fuerzas puso en juego esta doctrina? Las doctrinas militares han sido producto de un complejo proceso de elaboración que, si bien tuvo a Estados Unidos como un actor clave, involucró aspectos sociohistóricos locales, regionales e internacionales. Nuestro trabajo se enmarca en ese supuesto e intenta aportar a la complejización del "sentido común académico" respecto a la DSN en Centroamérica y a los procesos de elaboración doctrinaria castrense en los años setenta y ochenta a partir del estudio de las Fuerzas Armadas guatemaltecas. Concretamente, nos proponemos mostrar, a partir del análisis de diez tesis de ascenso de oficiales del Ejército de Guatemala, que, en el período 1975-1985, se desató una preocupación por parte del Alto Mando del Ejército, y de la oficialidad en general, por establecer una serie de definiciones políticas y técnicas necesarias para establecer una doctrina propia que guiara el accionar militar. En segundo lugar, exponemos las diferencias de enfoques prevalecientes entre los oficiales respecto a la conceptualización de los conflictos a atender por las Fuerzas Armadas y los métodos y formas de enfrentarlos. Por último, 
identificamos las referencias bibliográficas de las que se nutrieron los oficiales en cada tesis. En ese recorrido, mostramos la destacada lectura de textos de militares sudamericanos y taiwaneses.

El corpus documental de este trabajo constituye su mayor riqueza: diez tesis de ascenso de oficiales de las Fuerzas Armadas guatemaltecas escritas entre 1975 y 1985. Estas son fuentes muy poco exploradas que permiten adentrarnos en el pensamiento de la oficialidad guatemalteca. ${ }^{1}$

El período de estudio no es accidental. A mediados de los años setenta irrumpió en Guatemala la segunda generación guerrillera. Su confluencia con las organizaciones de masas hacia fines de la década dio lugar a una "coyuntura revolucionaria" (Thomas, 2013) que alertó a las Fuerzas Armadas. La escalada revolucionaria en El Salvador y Nicaragua imprimió en el movimiento revolucionario armado local mayor capacidad de crecimiento y expansión. La respuesta fue una represión de magnitudes inéditas dirigida por las Fuerzas Armadas, que desembocó en un genocidio (Figueroa Ibarra, 2012; García, 2005; Vela, 2014). Si bien el proceso represivo y la violencia estatal fueron constantes desde el derrocamiento de Jacobo Arbenz en 1954, a partir de 1978 y hasta aproximadamente 1985, las prácticas represivas adquirieron rasgos cuantitativa y cualitativamente distintos. Es decir, en esos años se produce una reconfiguración del aparato represivo estatal —y paraestatal — dominado por las fuerzas armadas. Proceso que involucró, necesariamente, aspectos técnico-operativos e ideológico-doctrinarios. Este trabajo aporta, en última instancia, al análisis de este proceso.

La idea de doctrina militar que guía este artículo fue planteada por Ernesto López $(1985,1987)$ en el marco de su trabajo sobre las intervenciones militares en el sistema político en América Latina. Según López, la doctrina militar se constituye a partir de proposiciones no necesariamente escritas que constituyen un corpus más o menos coherente con el fin de orientar a los militares en su accionar institucional.

1 He trabajado con algunas Tesis de Ascenso en Sala, 2017; 2018b. 


\section{6 / Laura Yanina Sala}

La doctrina expresa una concepción de la guerra o de los conflictos militares más probables y una concepción de la nación. Identifica enemigos específicos, detecta aliados en el escenario internacional y fija criterios para la organización de las fuerzas armadas. Fija, además, la relación que las fuerzas deben mantener con el sistema político (López, 1985, pp. 103-105). En la mirada de López, por ende, las doctrinas contienen aspectos técnico-militares y otros de tipo político-militar. Ambos están interconectados. No puede pensarse la forma en que las Fuerzas Armadas ejercen la violencia estatal sin considerar los aspectos políticos que forman parte de su doctrina.

El trabajo se divide en tres partes. La primera analiza breve y críticamente las posiciones dominantes respecto a la Doctrina de Seguridad Nacional, cuáles son sus componentes principales, sus orígenes y formas de circulación. La segunda describe el corpus documental, las tesis de ascenso, en el que se basa el argumento del trabajo y fundamenta su elección como una forma de acceso al pensamiento doctrinario de las Fuerzas Armadas. La tercera parte analiza las tesis con el propósito de mostrar: a) cómo las Fuerzas Armadas avanzaron en la búsqueda de una doctrina propia, b) las diferentes posturas que se formularon respecto a la caracterización del conflicto y a la forma de combatirlo y c) sus influencias bibliográficas. Por último, apuntamos algunas reflexiones finales.

\section{Planteos dominantes respecto a la Doctrina de Seguridad Nacional}

Los textos más influyentes sobre la DSN en América Latina han identificado sus características principales (Calvo, 1979; Chateau, 1983; Comblin, 1976, 1978, 1979; Maira, 1990; Nina, 1979; Tapia Valdés, 1980; Velásquez Rivera, 2002). Entre sus “componentes” destacaron, en primer lugar, la preeminencia en la DSN de una idea de la Guerra Fría basada en la "bipolaridad del mundo" asimilada con el conflicto Este-Oeste, el cual se asume como un hecho dado que involucra — desde afuera - a las naciones latinoamericanas. En segundo lugar, una concepción organicista de la "nación” y el "Estado". La "nación” 
aparece como una sola voluntad, uno solo proyecto cuya manifestación es el Estado. Como tercer componente, aparece una idea nueva de guerra centrada en la noción de "enemigo interno". Esta nueva noción de guerra asumió diversos adjetivos ("total", "revolucionaria", "estratégica", "integral”), pero en todos los casos supone una cuestión técnica novedosa: el enemigo se infiltra entre la población y busca su apoyo. A partir de estos "componentes", según los análisis en estudio, surgen los "elementos" de la DSN, a través de los cuales se hacen operativos los conceptos recién señalados: "objetivos nacionales", "seguridad nacional", "poder nacional" y "estrategia nacional". Los "objetivos nacionales" tienen que ver con el deseo de nación que se tenga. Se establecen desde el Estado. El "poder nacional" remite a "la suma de las potencialidades naturales, económicas, psicológicas y militares que el país tiene a su disposición y que constituyen sus instrumentos estratégicos" (Tapia Valdés, 1980, p. 117). La "seguridad nacional" implica, entonces, garantizar a través del "poder nacional" y en función de una "estrategia nacional", los “objetivos nacionales". La "seguridad nacional" es la capacidad del Estado para imponer sus objetivos a pesar de sus oponentes. Son las Fuerzas Armadas, según la DSN, quienes tienen la capacidad de hacer frente a este nuevo conflicto. Deben luchar en una guerra dentro de sus fronteras. Se erigen como salvadoras de la "nación" ante la penetración interna del comunismo internacional.

Como se ve, el énfasis en la caracterización de la DSN está puesto en las ideas de carácter político-ideológico que la constituyen. Jorge Tapia Valdés (1980) concluye que la DSN no es una doctrina militar para la guerra, "sino una doctrina política para los militares, gestada en Estados Unidos y dirigida a motivar la intervención pseudo-autónoma de los militares latinoamericanos" (p. 99). De allí nace el nuevo papel político del militar latinoamericano propuesto en la DSN como el salvador, como única fuerza capaz de combatir al "enemigo interno" y de mantener la estabilidad política. Si bien se remarcan orígenes diversos de sus componentes - por ejemplo, según el clásico trabajo de Joseph Comblin (1979), el concepto de "nación-Estado" es retomado de la geopolítica alemana y el de "bipolaridad", de la geopolítica inglesa y norteamericana-, se considera que adquieren "importancia en 


\section{I Laura Yanina Sala}

América Latina cuando los EE. UU., luego de la Revolución cubana, empiezan a promover la idea y también la capacitación y los recursos de la "counterinsurgency" (Chateau, 1983, p. 1). Estados Unidos es el gran ensamblador y difusor de la DSN. En esa línea, Comblin es enfático: "la DSN es una doctrina americana. Los latinoamericanos no han inventado nada. Aún más, han modificado muy poco la doctrina que recibieron completamente hecha de los Estados Unidos" (1979, p. 15). Se señalan tres "vías de transmisión" de la "doctrina" hacia Latinoamérica: las reuniones de jefes militares, los programas de ayuda militar o venta de armas y el entrenamiento de oficiales y otros especialistas en las escuelas militares norteamericanas.

Estos trabajos construyen su argumentación enfocándose en la política norteamericana para la región, más que en la relación entre esta y la propia dinámica de los países latinoamericanos. Si lo pensamos desde las teorías sobre circulación de ideas, estos trabajos explican la doctrina latinoamericana a partir del “campo de producción” (Bourdieu, 2017) situado en Estados Unidos desconsiderando el de la "recepción". De allí resulta, muchas veces, una concepción instrumentalista sobre las Fuerzas Armadas según la cual estas no serían más que un receptor pasivo de un cuerpo de ideas provenientes del Norte.

Esta mirada, no obstante, se fue complejizando desde diversas perspectivas a medida que se tuvo acceso a documentos oficiales y otras fuentes de las fuerzas armadas latinoamericanas. David Pion-Berlin (1989) fue uno de los primeros en matizar las miradas más monolíticas de la DSN y dio cuenta de sus variantes entre los países latinoamericanos conforme se mezcló con ideologías conservadoras (línea dura) o progresistas (línea blanda de la DSN). Pion-Berlin sostuvo que para entender esta doctrina hay que mirar, además de los manuales del Ejército estadounidense, las revistas militares latinoamericanas, especialmente las de Brasil, Perú, Chile y Argentina (Pion-Berlin, 1989). Las investigaciones sobre la influencia de la llamada "teoría" contrasubversiva francesa en Argentina (Mazzei, 2002; Périès, 1999, 2009; Ranalletti, 2018; Robin, 2014), en Guatemala (Drouin, 2017) o en Brasil (Nabuco de Araujo, 2012, 2016) han colaborado, a su vez, para matizar el rol de Estados Unidos en la influencia doctrinaria en 
América Latina. Ernesto López (1987) había advertido tempranamente sobre la influencia francesa en Argentina con anterioridad a la norteamericana y con objetivos distintos al combate "subversivo": "desperonizar" al Ejército. Otra línea de investigación reciente que aborda las relaciones entre las Fuerzas Armadas argentinas y centroamericanas, por su parte, ha puesto en evidencia otra forma de circulación de ideas y técnicas militares entre países "periféricos" hasta ahora poco explorada (Armony, 1999; Rostica, 2016, 2018; Sala, 2018a). ${ }^{2}$ Los trabajos que analizan las experiencias nacionales han dado cuenta, asimismo, de la complejidad de las elaboraciones doctrinarias. Para el caso guatemalteco — que es el que nos ocupa aquí - la producción de Gabriel Aguilera Peralta (2012) sobre el pensamiento militar o los trabajos clásicos que indagan en los "proyectos políticos" de los uniformados como los de Héctor Rosada Granados (2011) y Jennifer Schirmer (1999), recuperan la visión del actor militar y muestran, desde diversos enfoques, la complejidad del pensamiento militar.

Todos estos trabajos han mostrado que los fundamentos ideológicos de los procesos represivos implementados por las fuerzas armadas latinoamericanas se configuraron a partir de un proceso que no se restringió a la importación y absorción directa de las ideas estadounidenses. No obstante, como señalamos más arriba, esta sigue siendo la perspectiva dominante sobre el tema para pensar los casos centroamericanos. Las fuerzas armadas centroamericanas parecen haber incorporado de forma pasiva, acrítica y textual un bloque de ideas proveniente de Estados Unidos. Esta mirada no reconoce capacidad de agencia a los ejércitos de la región, invisibiliza los contextos y las producciones ideológicas locales, desestima las condiciones sociohistóricas, las disputas entre actores y los objetivos con que los actores locales recibieron las ideas de la seguridad nacional norteamericana. A la vez, la mirada centrada en la posición de EE. UU. desdibuja el rol que las relaciones entre estos países y otros de América Latina

\footnotetext{
2 La investigación, especialmente periodística y judicial, sobre las relaciones entre las dictaduras latinoamericanas se centró en la coordinación represiva en el Cono sur, especialmente en la llamada Operación Cóndor (Calloni, 2001; López, 2016; Martorell, 1999; McSherry, 2009; Padrós \& Slatman, 2012).
} 
y extracontinentales tuvieron en la elaboración político-doctrinaria local. En suma, simplifica la forma en que se construyeron, circularon y se retroalimentaron las ideas que dieron forma a las doctrinas militares del período. En este trabajo mostramos cómo, en el período de estudio, los militares guatemaltecos interpelados por una coyuntura novedosa, se abocaron a la construcción de una doctrina propia, retomando aspectos doctrinales de diversas instituciones militares, además de las absorbidas por la vía norteamericana. Proceso que involucró diferencias y disputas que se reconocen en posicionamientos diversos respecto al "problema subversivo", identificados como "desarrollistas", "políticos" y "militaristas". Las tesis de ascenso de los oficiales constituyen nuestra puerta de entrada al pensamiento militar en Guatemala.

\section{Las tesis de ascenso. Breve caracterización del corpus documental}

La elaboración de una tesis constituye uno de los requisitos para ascender al grado de Coronel del Ejército guatemalteco según lo establece el Reglamento de Ascensos vigente en nuestro período de estudio (Artículos 7, 10 y 13 del Acuerdo Gubernativo 3-80). ${ }^{3}$ En Los pelotones de la muerte, Manolo Vela logró reconstruir con claridad el lugar de la oficialidad en el despliegue militar en Guatemala: los coroneles eran quienes ocupaban los cargos ejecutivos de brigada y de comandantes de las brigadas militares: las posiciones más importantes en el despliegue territorial del Ejército. Eran, además, los jefes de las direcciones del Estado Mayor General del Ejército (a partir de

\footnotetext{
3 Los ascensos en la escala jerárquica del Ejército tienen como requisito, entre otros, el de "capacidad profesional", acreditada con los cursos impartidos por el Centro de Estudios Militares o escuelas militares similares (artículo 10 del Reglamento de Ascenso. Acuerdo Gubernativo 3-80). Según establece el artículo 13, "la escala de los cursos para los diferentes grados será la siguiente: Para el ascenso a Capitán Segundo: Curso Básico. Para el ascenso a Capitán Primero: Examen de Planas Mayores; Para el ascenso a Mayor: Curso Avanzado. Para el ascenso a Teniente Coronel: Curso de Comando y Estado Mayor. Para el ascenso a Coronel: Tesis sobre un tema fijado por el Estado Mayor General del Ejército" (artículo 13 del Reglamento de Ascenso. Acuerdo Gubernativo 3-80).
} 
1983, denominado Estado Mayor de la Defensa Nacional). Es decir, los coroneles eran los cuadros de dirección de la institución armada que llevaría adelante el genocidio. ${ }^{4}$ Las tesis de ascenso nos permiten, entonces, adentrarnos en su pensamiento.

Las tesis constituyen documentos "confidenciales". Su autor aparece identificado con una clave. El tema de cada tesis es otorgado al oficial tesista por el Estado Mayor de la Defensa Nacional. Ello permite argumentar que los temas de las tesis reflejan los intereses del Estado Mayor. El tema es, al mismo tiempo, el título de la tesis. Los títulos se formulan como hipótesis o prescripciones sobre las que el autor debe argumentar. Por ejemplo, en la tesis titulada Necesidad de mantener oficiales trabajando en los ministerios, el autor se dedica a argumentar por qué es necesario mantener militares en la administración pública. El formato de las tesis incluye una introducción - y en algunos casos un prólogo-, el desarrollo del tema en diferentes capítulos, conclusiones y, por último, las recomendaciones del autor respecto del tema estudiado.

Para este trabajo se analizaron las siguientes tesis: Clave A-51 (1975) Influencia de los problemas socio-económicos de Guatemala en la guerra subversiva; Clave CA-3097 (1977) Importancia y necesidad militar de mantener oficiales trabajando en los ministerios de estado; Clave CA-2597 (1977) Seguridad Nacional; Clave I01X-79 (1979) Necesidad de desarrollar en el ejército una doctrina de guerra política; Clave 108X79 (1979) Proyecciones del curso kaibil en el ejército de Guatemala; Clave I09X80 (1980) La guerra de guerrillas en la lucha subversiva; Clave I 10 x 80 (1980) Comunismo y subversión; Clave I21x81 (1981) Cómo erradicar la subversión en el departamento de Chimaltenango; (1982) Estudio de la doctrina de contrainsurgencia 1960-1982; y Clave I-37-X-85 (1985) Análisis de táctica y estrategia empleada por el ejército de Guatemala, en la lucha contrasubversiva de 1962 a la actualidad.

La selección se hizo con base en el catálogo de tesis de ascenso disponible en la Biblioteca del Estado Mayor de la Defensa Nacional

$4 \quad$ Véase Vela, 2014, p. 165. 
de Guatemala donde se encontraban resguardadas al momento de la consulta. Estuvo guiada en función de dos criterios básicos orientados por el objetivo principal del trabajo aquí presentado y el concepto de doctrina que utilizamos: 1) que las tesis seleccionadas abarquen todo el período de estudio; y, 2) que aborden aspectos doctrinales, políticomilitares y técnico-militares, relacionados con la conflictividad interna.

Es importante aclarar que no tenemos certezas respecto a las características del catálogo. No sabemos si contempla todo lo escrito o solo una parte, o si hubo algún proceso de selección de las tesis para catalogarlas y guardarlas. A pesar de ello, creemos que es posible extraer algunas conclusiones certeras respecto de nuestros objetivos. La consulta se realizó in situ en los meses de enero, febrero, octubre y noviembre de 2016.

El catálogo contempla tesis a partir del año 1970, año de creación del Centro de Estudios Militares (CEM). Entre 1970 y 1996, año de la firma de los Acuerdos de Paz, se escribieron 362 tesis en total. En el período que nos interesa - los diez años transcurridos entre 1975 y 1985 - se escribieron 125 tesis de ascenso, aproximadamente el $34,5 \%$ del total registrado hasta 1996, distribuidas de manera muy desigual. Los años 1977 y 1981 fueron los años de mayor producción: veintidós y veintiún tesis respectivamente. En los años previos, desde 1970 a1974 se escribieron 9 tesis y en el período posterior, en los diez años transcurridos entre 1986 y 1996, 227 tesis (casi el 63\% del total). Si se observa la figura 1 a continuación se verá que, a partir de 1985, la producción aumenta de manera más sostenida. 
Figura 1. Cantidad de tesis por año, 1970 - 1996

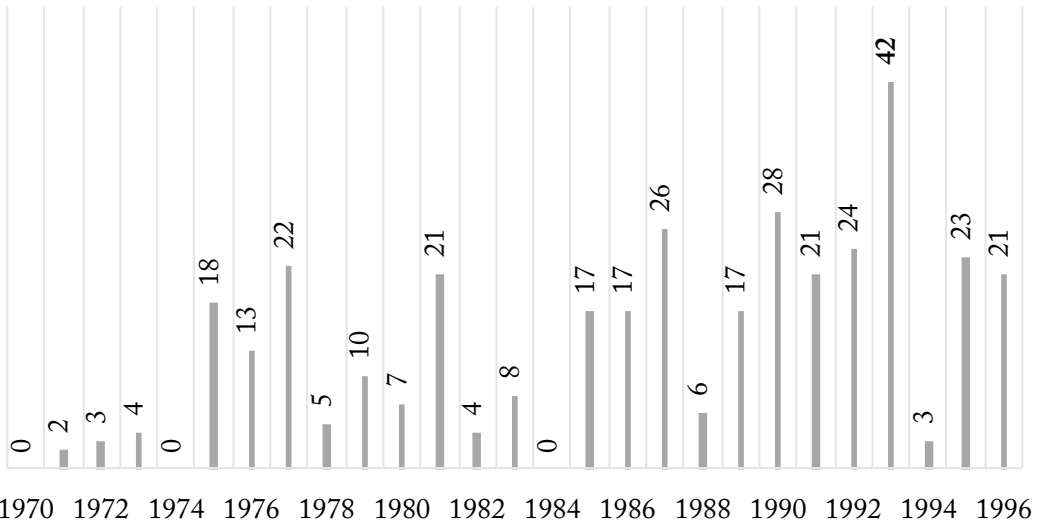

Fuente: elaboración propia con base en el catálogo de tesis de ascenso de la Biblioteca del Estado Mayor General del Ejército de Guatemala.

Para poner en perspectiva las tesis seleccionadas y justificar nuestra selección, elaboramos una clasificación de los temas/títulos de las tesis desde 1970 hasta 1996. Con base en una visión general de los títulos y en el resumen de las tesis y nuestros objetivos de trabajo construimos cinco categorías: a) organización de la fuerza; b) conflictos y/o hipótesis de guerra; c) otros estudios político-militares; d) estudios estratégicos nacionales; y e) estudios estratégicos regionales e internacionales.

La categoría a) "organización de la fuerza" incluye a aquellas tesis que abordan la estructura y organización interna del Ejército. Esto es, la planificación, evaluación y control de la organización, el personal y el equipo del Ejército. Abarca tesis sobre la formación, salud y entrenamiento del personal; sobre formas de reclutamiento; sobre reorganización de servicios, evaluación de tablas de organización y equipo; control de abastecimiento, etc. La categoría b) "conflictos y/o hipótesis de guerra" contiene a todas las tesis que abordan cuestiones político-militares relacionadas con los conflictos vigentes, pasados o de previsible desarrollo en el fututo. Las subcategorías son b.1) nivel interno, dividida a su vez en "subversión" y "otros"; y b.2) nivel externo. La categoría c) "otros estudios político-militares" 
agrupa a las tesis que no abordan directamente hipótesis de guerra, pero que están estrechamente relacionadas con estas, y que son, más bien, reflexiones sobre cuestiones político nacionales como el "desarrollo" o la "integración". Agrupa las tesis que abordan la participación del Ejército en el desarrollo nacional o que analizan y discurren sobre los caminos del desarrollo o la "integración nacional". La categoría d) "estudios estratégicos nacionales" incluye las tesis que realizan análisis de zonas y áreas de diferentes regiones o departamentos del país y estudios estratégicos a nivel nacional. La categoría e) "estudios estratégicos regionales e internacionales" incluye las tesis que realizan análisis estratégicos de países limítrofes, de la región o de nivel internacional.

En la siguiente tabla se puede ver la distribución de las tesis por categoría de temas en cada período:

Tabla 1. Tema de tesis por período

\begin{tabular}{|c|c|c|c|c|c|c|c|c|c|c|}
\hline & \multicolumn{3}{|c|}{$\begin{array}{l}\text { Organización } \\
\text { Interna }\end{array}$} & \multirow{3}{*}{$\begin{array}{l}\text { b. Otros } \\
\text { aspectos } \\
\text { pol- } \\
\text { militares }\end{array}$} & \multicolumn{3}{|c|}{$\begin{array}{c}\text { c. Conflictos y/o } \\
\text { hipótesis de guerra }\end{array}$} & \multirow{3}{*}{$\begin{array}{c}\text { d. } \\
\text { Estudios } \\
\text { estrat. } \\
\text { nacionales }\end{array}$} & \multirow{3}{*}{$\begin{array}{c}\text { e. } \\
\text { Estudios } \\
\text { estrat. } \\
\text { regional- } \\
\text { mundial }\end{array}$} & \multirow{3}{*}{ Totales } \\
\hline & \multirow{2}{*}{ Personal } & \multirow{2}{*}{$\begin{array}{c}\text { Estruc } \\
\text { y Org }\end{array}$} & \multirow{2}{*}{ Equipo } & & \multicolumn{2}{|c|}{ Internos } & \multirow{2}{*}{ Ext. } & & & \\
\hline & & & & & Subversión & otros & & & & \\
\hline $1970-$ & 2 & 1 & 0 & 0 & 0 & 0 & 0 & 3 & 3 & 9 \\
\hline 1974 & $22,2 \%$ & $11,2 \%$ & $0 \%$ & $0 \%$ & $0 \%$ & $0 \%$ & $0 \%$ & $33,3 \%$ & $33,3 \%$ & $100 \%$ \\
\hline 1975- & 24 & 13 & 4 & 14 & 31 & 0 & 2 & 10 & 5 & 125 \\
\hline 1985 & $22,5 \%$ & $12 \%$ & $8,5 \%$ & $13 \%$ & $25 \%$ & $0 \%$ & $2 \%$ & $9,4 \%$ & $4,6 \%$ & $100 \%$ \\
\hline 1986- & 66 & 71 & 10 & 43 & 23 & 4 & 0 & 3 & 6 & 226 \\
\hline 1996 & $29 \%$ & $31,5 \%$ & $4,5 \%$ & $19 \%$ & $10 \%$ & $1,7 \%$ & 0 & $1,3 \%$ & $3 \%$ & $100 \%$ \\
\hline
\end{tabular}

Fuente: elaboración propia con base en el catálogo de tesis de ascenso de la Biblioteca del Estado Mayor General del Ejército.

Esta clasificación nos permite argumentar uno de los puntos que nos proponemos demostrar: en nuestro período de estudio la reflexión políticomilitar y técnica sobre la "guerra interna" aumenta considerablemente y comienza a disminuir a fines de los años ochenta.

Como se ve en la tabla, las pocas tesis escritas entre 1970 y 1974 , se dividen en estudios estratégicos locales y regionales y aspectos de organización interna de las Fuerzas Armadas. En nuestro período 
de estudio, entre 1975 y 1985, los temas relacionados con la estructura y organización interna del Ejército siguieron ocupando un lugar destacado. Fueron importantes, a su vez, los estudios estratégicos de zona y área con un 9,4\%. En este período aparecen, asimismo, trabajos sobre Belice, ausentes en el período anterior y posterior. No obstante, lo más destacado es que se inauguran las tesis que reflexionan sobre los diversos aspectos de la "guerra subversiva" (25\%), y otros aspectos políticos militares (13\%). Entre estas dos categorías (b y c) suman casi el $40 \%$ de las tesis. Es decir, las tesis empiezan a aportar reflexiones de tipo doctrinario, ausente en los años anteriores. Entre las tesis que se ocupan de "otros" aspectos políticos militares predominan las que abordan la relación del Ejército con el desarrollo o la "integración nacional" como, por ejemplo, Proyección del Ejército alproceso de desarrollo nacional, El Ejército como factor en la integración social nacional, ambas del año 1977, o El Ejército nacional base del desarrollo socio-económico de Guatemala del año 1978.

A partir de 1986, año de "implantación" de la institucionalidad política democrática (Torres-Rivas, 2007), cobran mayor centralidad los estudios sobre la estructura y organización interna del Ejército (65\%) y disminuyen los estudios estratégicos. La categoría c) "Conflictos e hipótesis de guerra" también disminuye en términos porcentuales: las tesis referidas a la "guerra subversiva" pasan del 25\% al 10\%, pero aparecen tematizados otros conflictos internos, particularmente el narcotráfico $(1,7 \%)$. No obstante, la reflexión sobre los aspectos político-militares (categorías b y c) sigue ocupando, en su totalidad, un lugar importante con el 30,7\% de las tesis. Mientras las producciones sobre la "guerra subversiva" disminuyen, aumentan las tesis sobre "otros aspectos político-militares" (del 13 al 19\%). En este punto, las reflexiones del Ejército se orientan progresivamente a identificar nuevas funciones en el marco del avance del Proceso de Paz, la pacificación regional y el fin de la Guerra Fría. Las tesis abordan, por ejemplo, la Importancia del Ejército de Guatemala como garante de la supervivencia del Estado (1989); Posición del Ejército de Guatemala dentro de un gobierno democrático (1990) y La función del Ejército de Guatemala en la década 1991-2000 (1991). 
En resumen, el período en que mayor reflexión hubo en el interior del cuerpo de oficiales sobre "conflicto e hipótesis de guerra" (categoría c) fue entre 1975 y 1985. Las diez tesis seleccionadas corresponden a esa categoría en el período señalado. Ahora bien, ¿Cuál es el planteo de estas tesis? ¿Cómo se define el conflicto interno: la "guerra interna" o la "guerra subversiva"? ¿Hay homogeneidad en los planteamientos entre las diferentes tesis? ¿Cuáles son sus influencias? Finalmente, ¿se puede hablar de la existencia de una doctrina?

\section{El proceso de reformulación del pensamiento político-militar del Ejército: hacia una doctrina propia}

\section{La revisión crítica: "No estamos preparados para la guerra"}

Todas las tesis de ascenso que son analizadas en este artículo abordan la llamada "guerra subversiva" desde diversos ángulos. El recorrido por las tesis muestra, en principio, una revisión crítica por parte de los oficiales respecto de las ideas, la actuación y la organización militar. En todas las tesis se lleva adelante una crítica a alguno de los aspectos que hacen a las Fuerzas Armadas y a su capacidad para enfrentar el estallido revolucionario de finales de la década del setenta. Aparecen, ante una realidad que demanda reacciones urgentes, "debilidades" y "ausencias", "errores y confusiones" y "métodos arcaicos", en clave de constataciones que suponen la necesidad de cambios en la institución armada. En algunos casos, incluso, estas constataciones aparecen como las causas del resurgimiento guerrillero. Las críticas abarcan desde aspectos relacionados con la conducción política del país hasta cuestiones puramente doctrinarias o referidas al entrenamiento o, incluso, a la capacidad de los comandantes. "La mayoría de los entrevistados coincidieron", dice el autor de la tesis Proyecciones del curso Kaibil: "[...] que de darse una nueva situación de resurgimiento de subversión [...] no estamos preparados" (Clave 108X79, 1979, p. 13).

La particularidad es que dichas críticas no son homogéneas ni unidireccionales. Dan cuenta, así, de que la propia reorganización del 
Ejército está en disputa. A continuación, se enumeran, a modo de ejemplo y sin pretender exhaustividad, algunas de estas constataciones:

\section{No hay doctrina}

Una de las más repetidas críticas de la oficialidad es la falta de doctrina que guía el accionar de las Fuerzas Armadas en general y de los soldados y oficiales en particular. En la tesis Seguridad Nacional, su autor, amparado en las ideas de la Escuela Superior de Guerra de Brasil sobre seguridad nacional, afirma que en Guatemala no hay una doctrina sobre este tema:

[...] no ha existido un pensamiento integral que haya abarcado los dos ámbitos del planeamiento (desarrollo y seguridad), y orientara los cinco campos de la conducción nacional (interior, exterior, económico, defensa y trabajo) (Clave CA-2597, 1977, pp. 20-21).

En esta tesis se reconoce la dificultad del establecimiento de una doctrina:

Establecer doctrinas de seguridad no es un problema simple. [...] La elaboración de una doctrina de Seguridad Nacional, por su mismo contenido e importancia, comporta un proceso sistemático de muchos años de experiencia (Clave CA-2597, 1977, pp. 58-59).

Para ejemplificar, el autor refiere al largo proceso en el que se vieron inmersas la Fuerzas Armadas norteamericanas y brasileras hasta llegar a una doctrina propia.

La falta de doctrina refiere en la tesis Seguridad Nacional a la necesidad de planificación y definición de estrategias que conduzcan al desarrollo y a la seguridad. En otros casos, la falta de doctrina se relaciona, más que con una idea integral de la seguridad y el desarrollo, con el tipo de guerra que el Ejército debe llevar adelante. En la tesis Necesidad de Desarrollar la Doctrina de Guerra politica... su autor sostiene que el Ejército debe, de manera urgente, implementar la doctrina de guerra política para librar la batalla contra el comunismo internacional y apuntalar la unión, moral y espíritu combativo en 
las Fuerzas Armadas. Afirma el oficial que "[...] la forma de guerra política es ideal para fomentar en el soldado el deseo de combatir" (Clave I01X-79, 1979, p. 36).

\section{No se forman buenos combatientes}

Ante el avance revolucionario en la región y en el país, dice el autor de la tesis Proyección del curso kaibil..., el Ejército debe prepararse porque los soldados y la oficialidad no están preparados para combatir: "[...] no estamos creando combatientes" (Clave 108X79, 1979, p. 18), sentencia. Lo único valioso que tiene el Ejército para hacer frente a una guerra de guerrillas es el curso Kaibil, propuesto por el Mayor Nuila Hub ante la evidencia de que los soldados no estaban preparados para combatir en una guerra de guerrillas. En caso de iniciarse una lucha contraguerrilla nuevamente, “[...] se corría con el peligro de volver a cometer errores [...] Dada la mentalidad de guerra convencional que se tenía" (Clave 108X79, 1979, p. 20). Se estaban enseñando: "[...] tácticas de defensa fija en contra-guerrillas, reforzar campamentos, construyendo posiciones defensivas. En la guerra de guerrillas es disparatada la defensa fija, ya que el guerrillero es libre" (Clave 108X79, 1979, p. 18). Pero, además, dice el autor: "A los soldados les enseñan tácticas de combates hombres que no tuvieron ocasión de combatir" (Clave 108X79, 1979, p. 18). Para este oficial, la condición necesaria para formar buenos combatientes es que los instructores hayan sido — ellos mismos — combatientes con experiencia en el norte y oriente del país.

\section{Métodos insuficientes}

En la tesis Necesidad de desarrollar la doctrina de guerra política, se plantea que en Guatemala se está enfrentando: “[...] una constante subversión comunista con métodos ortodoxos que esperan la situación en su punto desesperado, para hacer uso de las fuerzas armadas", mientras, dice el autor, los comunistas utilizan: “[...] refinados métodos que combinan la lucha armada con la guerra ideológica, que a través de la propaganda se introduce hábilmente" (Clave I01X-79, 1979, p. 11). El oficial enfatiza: 
nuestro método de lucha está desprovisto del ingrediente ideológico que fortalezca, motive al soldado combatiente y prevenga a la población. Falta pues la otra mitad de esta forma de guerra moderna que se ha denominado Guerra Política (Clave I01X-79, 1979, pp. 11-12).

\section{Improvisación}

Esta constatación es más drástica que las anteriores. No se habla de superar el "pensamiento convencional" o de cambiar los "métodos ortodoxos" sino que se plantea que el Ejército guatemalteco ha estado guiado por la improvisación. Algunos limitan la improvisación a áreas como la inteligencia, otros la aplican a toda la dinámica militar. Entre los primeros, por ejemplo, el autor de la tesis Proyección del curso Kaibil... afirma que "[...] debe volver[se] a poner en funcionamiento la Escuela de Inteligencia y Contra-inteligencia, ya que está comprobado que somos empíricos en esa área de combate" (Clave 108X79, 1979, p. 70).

La otra variante queda expresa en el Estudio de la Doctrina de Contrainsurgencia 1960-1982 de octubre de 1982, en la que se afirma que:

Después del análisis se observa que carecemos de doctrina, se nota la ausencia de lineamientos bien definidos, las directivas o sea los documentos en los cuales se asienta el núcleo de la idea para configurar un operativo, casi siempre se repite en su forma y contenido para operaciones diferentes. La mecánica operativa en altos y medios niveles de mando es más personal que técnica y algunas veces por falta también de doctrina, la concepción primaria de una situación, se distorsiona cuando llegaba a los grados subalternos; casi siempre nuestras operaciones han sido improvisadas y con diversidad de formas de actuar, la mayoría de veces se actuó por reacciones a las actividades del enemigo, nunca ha habido continuidad en las actividades de inteligencia y por épocas se ha carecido del respaldo del gobierno como un todo (sd, p. 3). ${ }^{5}$

5 Estudio de la Doctrina de Contrainsurgencia 1960-1982, octubre de 1982, p. 3. Es un estudio 
¿Qué implican estas constataciones? En principio, como ya se mencionó, una crítica a la organización y a la actuación del Ejército y una constatación de la necesidad de cambios ante la evidencia de que "no estamos preparados" para enfrentar a la subversión. No obstante, estas constataciones críticas respecto de la organización del Ejército in toto son, al mismo tiempo, una prescripción respecto de qué es urgente y necesario hacer y cómo hacerlo.

\section{Desarrollistas, guerreros y políticos}

Las tesis estudiadas, como dijimos previamente, prescriben los pasos a seguir de cara a enfrentar a la "subversión". Una mirada global de las mismas permite ver que lo que está en juego — en disputa- es la formulación de una doctrina propia. Como explica Ernesto López, las doctrinas militares se constituyen para dar respuesta a la función manifiesta principal de los ejércitos: hacer la guerra. Por lo tanto, caracterizan los conflictos militares más probables de una nación, definen hipótesis de guerra, identifican enemigos específicos, analizan el contexto internacional para detectar aliados y adversarios y fijan criterios para la organización de las Fuerzas Armadas (López, 1985, 103).

A partir de la lectura de las tesis se pueden identificar tres enfoquen que difieren en el énfasis que otorgan en sus consideraciones doctrinarias a aspectos relacionados con el desarrollo, a la disputa político-ideológica o a lo estrictamente militar. De ahí que los nombramos como "desarrollistas", "políticos" y "guerreros", respectivamente. Existen marcadas diferencias entre ellos respecto de la forma de comprensión del conflicto, y en los criterios para la (re)organización de la fuerza de cara a enfrentar la "subversión", es decir, en los métodos, las estrategias y tácticas, así como los aspectos relacionados con la formación de los soldados y oficiales. Todas las tesis cuentan con un capítulo dedicado a las recomendaciones en el que consta la propuesta del autor respecto a su tema. En ese apartado, que suele ser un resumen de lo ya introducido

elaborado por una comisión integrada por generales y oficiales superiores conforme el Oficio $N^{\circ} 3$ "N"- 000908 de fecha 9 de agosto de 1982. Se encuentra catalogado junto a las tesis de ascenso en la Biblioteca del EMDN. 
a lo largo de la tesis, aparecen sintetizadas sus miradas respecto a las estrategias, tácticas y técnicas para enfrentar exitosamente el conflicto.

Como se verá en la bibliografía de las tesis estudiadas, además de bibliografía del Ejército norteamericano se citan abundantes trabajos de autores o escuelas militares latinoamericanas y asiáticas. Al respecto, y de manera incipiente y general, podemos plantear que las posturas que representan estas escuelas o corrientes militares aparecen representadas-reformuladas en los diversos enfoques que se ponen en juego en las tesis estudiadas en el proceso de (re)formulación doctrinaria del Ejército guatemalteco. En el período de estudio que abordamos, los oficiales guatemaltecos establecieron relaciones con fuerzas armadas de diversos países de América Latina y Asia. Como es sabido, la llegada de James Carter a la presidencia de Estados Unidos (1977-1981) y su política exterior que condicionó el apoyo militar a la garantía de los derechos humanos, implicó una significativa reducción de la asistencia militar a Guatemala en asuntos de seguridad por parte de Estados Unidos. Este distanciamiento en el momento del estallido del segundo ciclo revolucionario en el país y de la crisis centroamericana, puede leerse como una de las condiciones que condujo a los guatemaltecos a buscar ayuda militar, de armamento y formación, en otros lugares del planeta. ${ }^{6}$ En el Estudio de la Doctrina de Contrainsurgencia 1960-1982 de octubre de 1982, se afirma que, durante el gobierno del general Fernando Lucas García, “[...] en vista de la seriedad de la amenaza de la guerrilla, [...] existió el interés en buscar asesoría con otros gobiernos, para la erradicación de la subversión" (sd, p. 42). Luego se destacan los "cursos de inteligencia y tácticas contraguerrilleras en la república de Argentina y Uruguay"(p. 23 del Anexo D). Pero la búsqueda de referencias, ayuda y asesoramiento por parte de las fuerzas armadas en este período no se agota ahí, sino que abarca también otros países latinoamericanos como Brasil, Colombia, Ecuador y Perú, y países asiáticos como Taiwán.

\footnotetext{
6 Las fichas de ascenso de los oficiales de Guatemala muestran esta diversificación de las influencias militares a través de los cursos que los oficiales realizaron en diferentes países de América Latina y Asia en este período. Véase el Fondo C.2.1.6.2-5-S005 "Fichas de Ascensos" del Archivo General de Centroamérica, Guatemala.
} 


\section{Los desarrollistas: énfasis en los aspectos socio-económicos}

Algunas tesis presentan una caracterización del conflicto a partir de la idea de la seguridad nacional según la cual, la seguridad de una nación, conforme se establece en la tesis Seguridad Nacional de 1977:

[...] no se trata más de una simple cobertura militar de la faja de fronteras terrestres o marítimas, sino más bien del fortalecimiento del potencial nacional dentro de la idea que se trata de preservar como un todo el organismo vivo del Estado, cubriendo la vulnerabilidad de cada uno de los sistemas que se integran (Clave CA-2597, 1977, pp. 14-15).

Esta perspectiva se apoya en la idea de que el conflicto varía en función de la relación seguridad-desarrollo. La falta de desarrollo o el subdesarrollo trae aparejada la posibilidad de conflicto:

La falta de desarrollo encierra, igualmente, el germen de la lucha. En el sub-mundo de la necesidad se generan sentimientos que suelen utilizar la violencia como válvula de escape, creando avenidas de aproximación por donde avanzan ideologías que justamente se apoyan en la frustración imperante (Clave CA-2597, 1977, p. 1).

Esa idea de seguridad viene, según el autor de la tesis, de los cambios en el mundo que llevaron a una transformación en la forma de la guerra. La guerra moderna es una guerra total, una guerra integral, que involucra a todos los campos nacionales (económico, sociales, psicológicos y políticos). Por ende, requiere una acción concreta por parte del Estado en cada uno de ellos para avanzar en el desarrollo nacional, y debe contemplar la participación de todos los grupos de poder.

Es una perspectiva anclada en las discusiones sobre el desarrollo, la modernización y la seguridad propia de esos años. El énfasis de esta perspectiva está puesto específicamente en los aspectos socio-económicos. De ahí que el conflicto permanece mientras permanezca el subdesarrollo que lo hace posible. La diferencia entre guerra y paz se desvanece. Aparece en esta tesis una idea que luego será repetida por 
el general Gramajo: "[...] por la integralización de la guerra; la política es ya considerada en antonomía (sic) a la expresión tradicional de Clausewitz [...] la continuación de la guerra por otros medios" (Clave CA-2597, 1977, p. 7).

La misma línea se observa, por ejemplo, en la tesis Influencia de los problemas socio-económicos de Guatemala en la guerra subversiva de 1975. Su autor afirma:

[...] si entendemos a cabalidad que la subversión es una consecuencia de problemas sociales y económicos de un pueblo, vamos a aceptar que estos movimientos serán una enfermedad endémica de los países en desarrollo" (Clave A-51, 1975, p. 38).

En esta tesis el autor enumera los "problemas sociales y económicos que influyen en la subversión en Guatemala” entre los que menciona:

[...] concentración de más del $70 \%$ de la tierra en muy pocas manos; subsistencia de relaciones económicas precapitalistas; subempleo y desocupación, falta de mano de obra tecnificada; economía dependiente y periférica; aislamiento rural por falta de medios de comunicación; población rural con hambre; insalubridad; partidos políticos sin patriotismo; Centralización completa de las actividades de gobierno, en la capital (Clave A-51, 1975, pp. 51-52).

Esta perspectiva otorga un lugar importante al Ejército a partir de tareas de acción cívica y de control y represión, pero reconoce la imposibilidad de una solución a largo plazo si el desarrollo no es una política de Estado en la que intervengan "todos los poderes nacionales". En la tesis Influencia de los problemas socio-económicos... su autor concluye:

[...] el Ejército juega un papel importantísimo, pero no está en capacidad de poder abarcar, por razones obvias. Es el Gobierno Central el único capaz de poder coordinar e impulsar los programas de desarrollo social, político y económico" (Clave A-51, 1975, p. 63). 


\section{4 / LaURa Yanina SaLa}

Las estrategias de la guerra, entonces, tienen su eje en torno a las acciones en pos del desarrollo económico y social. Su mirada no se limita al Ejército, sino que parte de una visión integral que abarque a todos los "factores de poder" de la nación. Por ejemplo, en la tesis Cómo erradicar la subversión en el Departamento de Chimaltenango su autor concluye que:

[...] la acción hasta ahora efectuada en esa región es en grado "altamente positiva" (área controlada), [...] pero determino que más que acción militar u operaciones, esa región requiere más que todo, acciones de gobierno proyectadas para beneficio de la comunidad [...] la región no necesita la determinante acción militar que otras áreas afectadas requieren (Clave I21X81, 1981, pp. 96-97).

Las tesis con enfoque desarrollista abarcan la primera etapa del período de estudio, entre aproximadamente 1975 y 1978. Las referencias bibliográficas de estas tesis — como puede apreciarse en la tabla Anexa a este texto-, están compuestas, por un lado, por literatura sociológica norteamericana y, por otro, por escritos militares latinoamericanos. Las principales referencias bibliográficas de la tesis Influencias de los problemas socio-económicos... provienen de la sociología norteamericana de los años cincuenta y sesenta que abordan modernización, desarrollo, cambio social y revolución, representada en autores como James C. Davies, Wilbert E. Moore, Frank Tachau y el referente de la Teoría funcionalista de la revolución: Chalmers Johnson. Aparecen referencias a Nathan Leites y Charles Wolf conocidos por su relación con la Rand Corporation. Por otro lado, y en menor medida, destacan algunas referencias a cuestiones estrictamente militares y estratégicas como el texto del Coronel estadounidense John J. McCuen, The art of counterrevolutionary war, textos específicos sobre guerrilla urbana como Philosophy of the urban guerrilla de Abraham Guillén o The urban guerrilla de Martin Oppenheimer, y el Manual de guerra contrasubversiva del Centro de Estudios Militares de Guatemala. Finalmente, algunas referencias al caso guatemalteco como Comunismo en Latinoamérica, el 
caso de Guatemala de Ronald Schneider e Integración social en Guatemala, un resumen del seminario de Integración social guatemalteca.

En la tesis Seguridad Nacional aparece con más claridad el enfoque militar de esta corriente desarrollista a partir de la idea de seguridad nacional, relativamente ausente en la anterior. Esta tesis hace referencia a literatura sobre planificación y geopolítica estadounidense con textos de Harris Seymour, N. Spykman y Hans Margenthau. El resto de la bibliografía está compuesta por escritos sobre "seguridad nacional" de militares argentinos y brasileros: La moderna Seguridad (1967) del entonces Coronel Arturo Enrique Barbieri, que versa sobre la relación entre desarrollo y planificación; ${ }^{7}$ La seguridad Nacional, la política y la estrategia del Mariscal Juarez Távora, y Seguranca Nacional, Antagonismo y vulnerabilidades (1958) del General Aurelio de Lira Tavares. ${ }^{8}$ Finalmente, el autor hace referencia a "Libros de Seguridad Nacional y Estrategia de las Escuelas Superiores de los siguientes países: Argentina, Brasil, Ecuador, Estados Unidos, Guatemala, Venezuela" (1977, p. 66).

\section{Los políticos: el énfasis en lo político-ideológico}

Otra conceptualización del conflicto pone el énfasis en el factor político-ideológico:

“[...] si examinamos la causa principal de las perturbaciones en todo el mundo vemos que reside en el conflicto de las ideas" (p. 2), afirma el autor de la tesis Comunismo y subversión de 1980. El comunismo y el "mundo libre" encarnan, según el autor, una lucha a nivel mundial. En esta visión del conflicto, las ideas, lo ideológico y lo político ocupan el

\footnotetext{
7 Arturo Enrique Barbieri fue Subjefe "A" del Estado Mayor del Ejército Argentino y se desempeñó en el Departamento de Política, Inversión y Desarrollo durante la dictadura de Onganía (1966-1969) y Secretario de Estado de Deportes y Turismo en la última dictadura argentina (1976-1983).

8 Juarez Távora fue el segundo Comandante de la Escuela Superior de Guerra de Brasil (1953-1955). Desde allí contribuyó de manera decisiva en la elaboración ideológica-doctrinaria de las Fuerzas Armadas de Brasil. Pertenecía al Partido Demócrata Cristiano (Mundim, 2015). Aurélio de Lira Tavares integró junto con Humberto de Alencar Castelo Branco la comitiva de oficiales que estudiaron en la Escuela Superior de Guerra de París. Fue Comandante de la Escuela Superior de Guerra de Brasil de 1965 a 1967, y fue miembro de la Junta Militar que gobernó Brasil desde agosto hasta octubre de 1969.
} 


\section{6 / Laura Yanina Sala}

lugar central. "[...] las tácticas de la guerra política se convirtieron en un instrumento importante para los comunistas en su lucha contra el mundo libre" (Clave I10X80, p. 10), sostiene el autor de la tesis Necesidad de desarrollar en el Ejército una Doctrina de guerra Política, de agosto de 1979. "Si uno dijera que la guerra militar es el cuerpo entonces la guerra política sería su alma", continúa afirmando el mismo autor (p. 24). El concepto de "guerra política", explica: "[...] incluye la guerra estratégica, la guerra ideológica, la guerra de organización, la guerra psicológica, la guerra de inteligencia y la guerra masiva [...]" (Clave I10X80, 1980, p. 20).

La guerra política envuelve dos ideas básicas: la primera, afirma el oficial, es que "estamos empeñados en un conflicto total" (Clave I10X80, 1980, pp. 13-14). Ello implica que “[...] aún en tiempos de paz cualquier arreglo o acomodo solo constituye una táctica, cuando estamos empeñados permanentemente en una contienda contra una potencia revolucionaria" (Clave I10X80, 1980, pp. 13-14). La segunda idea es que, como la guerra política es total "debemos hacer uso intensamente de todos los instrumentos del poderío disponibles al Estado, diplomacia, propaganda, guerra psicológica, presiones económicas y fuerzas militares" (Clave I10X80, 1980, pp. 13-14).

Esta perspectiva que enfatiza en la dimensión ideológica y política, otorga un lugar central al factor internacional. "[...] la lucha hoy día se desarrolla en todos los países del mundo; ya que es internacional, es civil y es revolucionaria" (I01X79, 1979, p. 14), afirma el autor de la tesis Necesidad de desarrollar en el Ejército...

En la tesis La guerra de guerrillas en la guerra contrasubversiva, de septiembre de 1980, su autor afirma que "el verdadero sentido de las luchas contemporáneas es el de las luchas por el poder" (Clave I09X80, p. 1). Pero no pueden restringirse al ámbito interno, no responden exclusivamente a cuestiones locales. Dice el oficial en ascenso:

La lucha de las organizaciones revolucionarias contra los ejércitos regulares $[\ldots]$ constituyen hoy una realidad cuya repercusión y dimensiones no se limitan exclusivamente a los ámbitos nacionales 
[...] Solo una visión integral de las determinantes internacionales del poder puede facilitarnos la comprensión de conflictos que, de otra manera, corremos el riesgo de interpretar como meras manifestaciones de desacuerdos folklóricos (Clave I09X80, 1980, p. 2).

La particularidad de este conflicto, al igual que la perspectiva que enfatiza en el desarrollo, es que no se termina con la paz. En términos esquemáticos, este enfoque plantea que la subversión se expande por el mundo a medida que se expande la ideología. En estas explicaciones la población es la llave a la victoria y la forma de lograr su adhesión es a través de la acción psicológica: "Las acciones psicológicas son el arma más importante de la subversión para afectar la mente del hombre y convertirlo en dócil instrumento de sus conveniencias" (Clave I09X80, 1980, p. 39) dice el autor de la tesis La guerra de guerrillas.... Las posturas que caracterizan el conflicto haciendo énfasis en la dimensión político-ideológica, están de acuerdo en que las estrategias y tácticas del Ejército deben hacer especial hincapié en la inteligencia, la acción psicológica y/o el juego político. En estas tesis predomina el supuesto de que controlar a la población es más importante que combatir al guerrillero: "[...] la retaguardia del enemigo es más importante que la vanguardia” (Clave I01X79, 1979, p. 16) afirma, citando a Chiang Kai- Shek, el autor de la tesis Necesidad de desarrollar en el Ejército una Doctrina de guerra Política. No obstante, a diferencia de las propuestas de acción centradas en el desarrollo económico o social, en esta perspectiva el aspecto puramente militar queda subordinado al trabajo político-ideológico sobre la población. La guerra política, enfatiza: "[...] es factor determinante para decidir la victoria o la derrota en la guerra" (Clave I01X79, 1979, p. 16). Es posible "[...] reducir al enemigo sin necesidad de presentar lucha" (Clave I01X79, 1979, p. 16). La guerra contra el comunismo, expresa: "[...] es una guerra en la que se combinan las fuerzas armadas con las masas y bajo los principios de: "30\% guerra militar y $70 \%$ (sic) guerra política” (Clave I01X79, 1979, p. 31).

En la misma línea, en la tesis La guerra de guerrillas en la guerra contrasubversiva, al citar a Roger Trinquier, uno de los ideólogos de la llamada "Teoría de la Guerra Revolucionaria" francesa, se afirma: 
"La guerra de contraguerrillas no es una batalla de carácter militar, sino una cuestión de métodos" (Clave I09X80, 1980, p. 5). Una de las cuestiones centrales es la protección de la población civil, con el objeto de "[...] aislar las guerrillas de su apoyo y tomar medidas de seguridad necesarias para evitar que interfieran las operaciones militares". Según el autor, las operaciones con ese fin "podrían ser ejecutadas por fuerzas paramilitares teniendo siempre la responsabilidad principal el Ejército para fines de control" (Clave I09X80, 1980, p. 38). No obstante, aclara, "debe insistirse sin descanso para que la misma población se proporcione su propia defensa o colabore en ella" (Clave I09X80, 1980, p. 38).

Las claves centrales en la guerra de contraguerrillas, según el autor de esta tesis, son la inteligencia y la contrainteligencia. La inteligencia debe garantizar un "completo conocimiento del área, la población y las fuerzas externas e internas que apoyan la subversión" (Clave I09X80, 1980, p. 32). Para ello, las operaciones “[...] tienen como fuentes principales de información las siguientes: a. El Prisionero; b. El Terreno c: La población” (Clave I09X80, 1980, p. 32). Acerca del prisionero, dice: “[...] Los interrogatorios pacientes y conducidos con habilidad inmediatamente después de la captura del guerrillero, pueden proporcionar la siguiente información: efectivos, armamento, movimientos, sistemas de abastecimientos, moral, etc." (Clave I09X80, 1980, p. 32). Sobre el terreno, "por la observación e interpretación de las modificaciones sufridas" (Clave I09X80, 1980, pp. 32-33) puede dar mucha información. $\mathrm{Y}$, acerca de la población, afirma:

[...] nos puede dar tres tipos de información: la observada, la confidencial y la confesión. La más importante es la observada porque permite muy poca oportunidad a la acción de la contrainteligencia enemiga (Clave I09X80, 1980, pp, 32-33).

En estas tesis, la formación militar debe tener como meta "soldados inteligentes": "Es preferible ser un pigmeo con inteligencia que un gigante embrutecido" (Clave I09X80, 1980, p. 40) dice el autor de la tesis La guerra de guerrillas en la guerra contrasubversiva. Sostiene que: 
"Mística, iniciativa, propaganda, inteligencia militar, astucia, unidades móviles de infantería, transmisiones y helicópteros" (Clave I09X80, 1980, p. 40) son las piezas más importantes "para ganar en este ajedrez denominado Guerra irregular, en el cual el débil puede derrotar al poderoso si este desconoce las reglas del juego" (Clave I09X80, 1980, p. 40).

Las siguientes tesis abarcan lo que podría denominarse la segunda etapa dentro de nuestro período de estudio, de 1978 en adelante.

Hay algunas tesis que combinan las perspectivas hasta ahora señaladas, aquellas que enfatizan en el desarrollo —escritas entre 1975 y 1978 - y aquellas que enfatizan en lo político-ideológico, escritas a partir de 1978. En la tesis Cómo erradicar la subversión en el Departamento de Chimaltenango, de agosto 1981, su autor entiende que la dimensión internacional y el plano ideológico son clave para comprender la "subversión": "Mientras exista Rusia y sus satélites, no se puede erradicar, más bien se puede 'minimizar' o contrarrestar o neutralizar la acción subversiva” (Clave I21X81, p. 3). El comunismo internacional dirigido desde Moscú y con plataforma para nuestra América Latina en la Isla caribeña de Cuba, dice el autor, viene desarrollando una estrategia subversiva que da lugar a una:

[...] guerra de tipo diferente librada en su mayor parte con técnicas no militares, tales como la subversión, la desinformación, el terrorismo, la guerra psicológica, las conferencias y las negociaciones diplomáticas (Clave I21X81, 1981, pp. 7-8).

Sin embargo, en su trabajo realiza un estudio detallado de Chimaltenago para argumentar que las características socio-económicas de este departamento constituyen el "terreno fértil" para la subversión. De ahí que concluya afirmando lo siguiente:

[...] la acción subversiva será difícil de erradicar mientras exista el peligro de la amenaza comunista o el comunismo internacional y más bien esa acción se podrá contrarrestar, minimizar o neutralizar, con las acciones de gobierno de índole político-social y económicas, 


\section{0 / LaURa Yanina SaLa}

encaminadas a mejorar las diferentes comunidades que conforman a la sociedad chimalteca (Clave I21X81, 1981, p. 103).

Lo destacable de esta tesis es que forma parte de un conjunto de tesis destinadas a pensar los planes de acción en cada uno de los departamentos del país. ${ }^{9}$

En estas tesis predominan las referencias a textos del Colegio de Guerra Política de Taiwán, y en menor medida de las fuerzas armadas sudamericanas. ${ }^{10}$ Por otro lado, comienzan a aparecer las lecturas del propio "enemigo", desde textos de Marx hasta documentos de las organizaciones revolucionarias guatemaltecas.

En la tesis Necesidad de desarrollar... de 1979 la mayor parte de la bibliografía está relacionada con el Colegio de Guerra Política de Taiwán. El autor cita el "Material de instrucción del Curso de Guerra Política", compilado por el Colegio Político del Ejército Chino en Taipei, Taiwán, en octubre de 1977, el texto Tácticas de Lucha Revolucionaria Mundial de los Comunistas Rusos de Wang Chueh-Yuan, publicado por la Liga Mundial Anticomunista en enero de 1976 y Teoría y Práctica de la Guerra política de Wang Sheng, General del Ejército Chino, elaborado por la Escuela de Guerra Política en julio de 1959 (Clave I01X79, 1979, p. 39). Por otro lado, aparecen referencias al Manifiesto Comunista de Marx y Engels, a Fundamentos de filosofía de Afanasiev V, y "Lecturas selectas sobre guerra contrasubversiva", elaborado por la Escuela de comando y Estado Mayor en enero de 1978.

\footnotetext{
$9 \quad$ En el año 1981 se escribieron numerosas tesis que buscaban responder a la pregunta sobre cómo erradicar la subversión para cada uno de los departamentos con presencia "subversiva".

10 La Guerra política fue una parte integral de la reforma militar de los nacionalistas desde que el triunfo del comunismo en la China continental, en 1949, los obligara a concentrarse en la isla de Taiwán. El Colegio de Guerra Política fue fundado en 1951. El objetivo fue contraponer una estrategia global de signo contrario a la estrategia de la "Guerra Revolucionaria" de los comunistas chinos. Taiwán fue el eje a partir del cual se organizó la Liga Anticomunista Mundial con vínculos estrechos en Centroamérica y Sudamérica. Sobre la Liga véase Anderson y Anderson, 1986.
} 
En la tesis Comunismo y subversión, vuelven a ser predominantes las citas al Colegio de Guerra Política de Taiwán. Nuevamente se cita Teoría y práctica de la guerra política del General Wang Sheng, y del mismo autor Estudio comparativo de los tres principios del pueblo con otras doctrinas. Se hace referencia a Acciones criminales de los comunistas chinos en su persecución religiosa de Shen Ping-Wen, Acerca de Teng Hsiao-Ping de Wag Hsuan, La Rusia soviética en China de Chiang Kai-Shek y Sistema comunista chino de reforma por el trabajo de Cheng Shu-Ping. Además, El pensamiento económico del siglo XX, Elpensamiento social del siglo XX, Elpensamiento político del siglo XX, Estudio de la táctica comunista y las medidas contraofensivas y Cuadros sinópticos de las doctrinas comunistas chinas, todos compilados por el Colegio Político de Taipei, Taiwán. Se hace referencia al texto La subversión de las Fuerzas Armadas del Uruguay, y a Organizaciones de fachada del comunismo internacional de Jorge Méndez. Por último, un bloque de textos sobre comunismo en Guatemala como El movimiento guerrillero en Guatemala de Adolfo Gilly, Renuncia al comunismo de Carlos Manuel Pellecer y a las tesis de ascenso Clave Q-1578, Estudio de la subversión comunista en Guatemala y Clave A-51, Infuencia de los problemas socio-económicos de Guatemala en la guerra subversiva a la que hicimos referencia en el apartado sobre desarrollistas.

En la tesis Guerra de guerrillas... no se consigna bibliografía, pero a lo largo del texto aparecen referencias a Roger Trinquier. Por último, las referencias bibliográficas de la tesis Cómo erradicar la subversión en el Departamento de Chimaltenango, se pueden ordenar en tres ejes: estudios de la zona: geográficos, censos, estadísticas y estudios socio-económicos del departamento de Chimaltenango; una serie de trabajos que caracterizan la "subversión" en América Latina y en Guatemala, tanto militares como de escritores no militares. Entre los escritos militares se encuentran las tesis de ascenso de oficiales guatemaltecos Estudio de la subversión comunista en Guatemala y Comunismo y subversión y otros trabajos de oficiales del Ejército. Luego refiere a ElTerrorismo en Argentina ${ }^{11}$ de las Fuerzas Armadas argentinas y al escrito La subversión de

\footnotetext{
11 Según la Memoria del Ministerio de Relaciones Exteriores y Culto de Argentina del año 1980, se envió el libro Terrorismo en Argentina producido por la Secretaría de Información Pública a todas sus representaciones diplomáticas.
} 
las Fuerzas Armadas de Uruguay. Respecto a los escritos no militares hay referencias a Geopolitica y subversión de José Teófilo Goyret y Derechos humanos y terrorismo de Ismael G. Montovío. ${ }^{12}$ Además, Tácticas rojas en las Américas de Daniel James y El mal latino de Alain Peyrefitte, Comunismo en Latinoamérica. El caso de Guatemala de R. Schneider. Asimismo, Elmovimiento guerrillero en Guatemala de Adolfo Gilly, entre otros. Por último, una serie de documentos oficiales de las organizaciones revolucionas FAR y PGT.

\section{Los guerreros: el énfasis en lo militar}

Las posturas que se enfocan en lo militar para explicar el conflicto, minoritarias entre las tesis estudiadas, parten de la idea de que la guerra desatada en Guatemala es una "guerra subversiva", cuyo origen es de carácter interno, pero no se relaciona con las condiciones socio-económicas o el subdesarrollo. Al igual que el enfoque político-ideológico, se asienta en la existencia de grupos ideológicos con pretensiones de poder, aunque en este caso, de carácter interno. En la tesis Proyección del Curso Kaibil... de 1979, su autor sostiene que la "guerra subversiva":

$[\ldots]$ es una guerra interna, no internacional (aunque tenga inspiración y apoyo exterior) orientada a la toma del poder para cambiar un sistema político [...] Es el recurso de grupos ideológicos que, por falta de apoyo popular o por acción de fuerza del grupo gobernante ven cerrado su acceso al poder por medios pacíficos (p. 7).

La mayor expresión de la guerra subversiva es la guerra de guerrillas. El punto central está puesto, entonces, en las características militarmente

\footnotetext{
12 Ambos libros forman parte de la colección argentina "Humanismo y Terror" compuesta por diez volúmenes, dirigida por Armando Piñeiro, publicada en 1980 por Editorial Depalma. Como afirma Carlos Gazzera, esa colección fue encargada con el intento de dotar a la última dictadura argentina (1976-1983) de un justificativo teórico y moral (Gazzera, 2006). En 1981, conforme surge de las Memorias del Ministerio de Relaciones Exteriores y Culto, en el marco del Plan de Comunicación Social 1979-1981, la cancillería argentina envió los diez volúmenes de la colección a la totalidad de las representaciones diplomáticas.
} 
distintivas del enemigo guerrillero. Para sobrevivir, dice el autor Proyección del Curso Kaibil, los guerrilleros:

[...] necesitan de todas sus fuerzas. Tiene que resistir largas marchas nocturnas [...] insuficiente alimentación. En los momentos de descanso se transforman en propagandistas. No tienen tiempo para ellos mismos. Ya no se pertenecen a sí mismos (108X79, 1979, pp. 11-12).

Es un conflicto que plantea una nueva forma militar de combatir, que su autor resume con la siguiente frase: "En la selva no hay política internacional que valga” (108X79, 1979, p. 46), es decir: se vale todo. Para enfrentar este tipo de guerra se requiere, fundamentalmente, soldados adecuados militarmente. Un soldado apto para encontrar, combatir y destruir, en el campo y la ciudad, a los grupos guerrilleros. "El punto básico para mí” dice el oficial de la tesis referida, “[...] es el soldado que ejecutará las órdenes y planeamientos de sus Generales" (108X79, 1979, p. 7).

En las tesis centradas en los elementos militares, lo fundamental es el combate y la eliminación militar del enemigo comunista. Se sostiene que la guerra subversiva es una guerra de guerrillas con combatientes con "ingenio, astucia y falta de escrúpulos", capaces de todo. Ello, dice el autor de la tesis Proyección del curso Kaibil..., hace necesaria una "defensa agresiva" que proyecte a todo el ejército, soldados, y oficiales, preparados para combatir física y mentalmente como un Kaibil. En última instancia, se afirma, es el soldado el que define la guerra:

[...] cuando las líneas de enlace se encuentran trastocadas, no pueden llegar ni órdenes ni refuerzos, cuando debido a la difícil situación de escases de energéticos los vehículos se inmovilizaren; entonces suena la hora para los soldados que lo han "aprendido" todo y que no "retroceden" nada. Soldado de ese tipo es el kaibil, el prototipo del soldado de mañana; preparado física, táctica y psicológicamente para vencer (Clave 108X79, 1979, p. 8). 
La postura militarista enfatiza en la formación militar física y en el adoctrinamiento del soldado, subestimando su formación intelectual. En la tesis de referencia su autor afirma "Mucho conocimiento ablanda el espíritu del guerrero" (Clave 108X79, 1979, p. 16). Este oficial propone la proyección del Curso Kaibil a todo el Ejército. Para su proyección en la Escuela Politécnica, donde "debe de terminarse con la formación de pre-universitarios de uniforme", propone seleccionar " $[. .$.$] a los mejores, experimentados y más drásticos 'kaibiles'$ para ocupar los puestos de comandos de unidad" (Clave 108X79, 1979, p. 65). Pero, dice el autor:

$[\ldots]$ solamente una instrucción formativa fuerte no es suficiente, ya que debemos de formar a nuestros futuros oficiales influyendo en su espíritu, actitudes, comportamiento y pensamiento [...] por lo tanto debe crearse también un centro de acción psicológica. Oficiales superiores que actúen como operadores psicológicos sobre la mente del Cadete durante toda la carrera de formación militar (Clave 108X79, 1979, p. 66).

El autor propone la instalación del curso Kaibil en nuevos centros de entrenamiento, junto con la reinstalación de la Escuela de Inteligencia y Contra-inteligencia para que se formen " [... agentes secretos adiestrados para asesinar, dinamitar, intimidar o neutralizar en la forma que se les ordene, el objetivo que se les señale" (Clave 108X79, 1979, p. 68). Asimismo, recomienda la creación de compañías kaibiles en todas las zonas, brigadas y bases militares; y, por último, propone que se le dé prioridad a los Kaibiles para que "[...] ingresen a policía militar ambulante, policía nacional, policías particulares o comisionados militares" (Clave 108X79, 1979, p. 74).

La bibliografía de esta tesis está compuesta por materiales militares relacionados con el combate militar y a la formación de los comandos. En la tesis están citados de la siguiente manera: "Material técnico y táctico de la Escuela de Armas del Centro de Estudios Militares de Guatemala, en sus Cursos Básico y Avanzado de Infantería" y "Material técnico, táctico y estratégico de la Escuela de las Américas del Ejército de Estados Unidos, en su Curso de Comando y Estado Mayor". 


\section{Reflexiones finales}

Si bien desde la creación del Centro de Estudios Militares en 1970 la elaboración propia de saberes militares fue un objetivo del Estado Mayor General del Ejército, la preocupación por la elaboración de una doctrina que guiara la lucha contra la subversión emergió con fuerza en el período aquí estudiado. El análisis de las tesis de ascenso de los oficiales del Ejército de Guatemala muestra cómo, en el marco de una preocupación creciente por el estallido revolucionario, los militares comienzan a revisar críticamente sus postulados. Las constataciones críticas a las que nos referimos revelan la necesidad de la oficialidad por construir parámetros nuevos y claros que guíen el accionar del Ejército para combatir a la subversión eficazmente; y, asimismo, para justificar entre los propios oficiales y soldados por qué se mata y por qué se muere.

A través de las tesis, a fin de establecer esos parámetros, el Alto Mando impulsó la construcción de saberes político-militares y técnico-militares por parte de su oficialidad. La particularidad, como ya lo mencionamos, es que los resultados no son axiomas uniformes y homogéneos a lo largo del período de estudio. Las diferencias centrales entre las tesis se encuentran en la forma de comprensión del conflicto, y en los criterios para la (re)organización de la fuerza de cara a enfrentar la "subversión". En el análisis diferenciamos tres posicionamientos u orientaciones: desarrollistas, políticos y guerreros. No hablamos de corrientes militares sólidas dado que el trabajo resulta todavía exploratorio en ese sentido y debería ser profundizado con el estudio de otras fuentes que permitan dar mayor consistencia a estas orientaciones. Preferimos, entonces, hablar de posicionamientos evidenciados en las tesis. Mientras los "desarrollistas" enfatizan en los déficits socioeconómicos vinculados al desarrollo como causa de la "subversión", los "políticos" lo hacen en los aspectos políticoideológicos y los "guerreros" lo reducen a la existencia de grupos armados con ansias de poder. Como vimos, estos diferentes focos en la explicación del surgimiento del conflicto se relacionan con diferentes formas de solucionarlo y diferentes roles para las Fuerzas Armadas. Las divergencias entre los posicionamientos reflejan las fuentes diversas a las que recurrió el Ejército guatemalteco para 


\section{6 / LAURA YANina SALA}

elaborar sus postulados doctrinarios y, a su vez, las disputas vigentes en su interior respecto a estos.

Asimismo, es importante reconocer que la variación entre las diferentes tesis tiene un eje temporal. Como mostramos a lo largo del texto, las tesis "desarrollistas" se ubican en la primera parte de nuestro período de estudio, entre 1975 y 1977. Estas se apoyaron en las ideas sobre seguridad, desarrollo y modernización que proliferaron en América Latina durante los años sesenta con textos de la sociología funcionalista norteamericana y las concepciones clásicas de seguridad nacional de militares argentinos y brasileros. Las otras dos, por su lado, aparecen a partir de 1978 y 1979, y están vinculadas a posturas militares contrasubversivas más específicas. En el caso de los "políticos", cobra relevancia la Escuela de guerra política de Taiwán y escritos de las fuerzas armadas sudamericanas de fines de los años setenta enmarcados en las llamadas "guerras sucias". En el caso de los "guerreros", aparecen en primer lugar materiales de formación práctica para el combate en una guerra irregular. En los dos últimos, "políticos" y "guerreros", las Fuerzas Armadas aparecen en el eje del combate contra la subversión mientras que entre los "desarrollistas" el rol del Ejército aparece guiando las cuestiones de desarrollo con la implicancia de todos los "poderes nacionales". Este viraje hacia posicionamientos que repiensan y refuerzan la acción del Ejército en su aspecto específicamente militar se corresponde con el contexto en el que surgen. Hacia 1978, las organizaciones revolucionarias habían logrado un alto grado de desarrollo y visibilidad, en un contexto regional caracterizado por la revolución nicaragüense y el estallido revolucionario en El Salvador. Las cuestiones necesarias de desarrollo parecían perder lugar ante las cuestiones urgentes de eliminación de la "subversión".

El Ejército guatemalteco parece no haber recibido acríticamente un corpus de ideas homogéneo por parte de Estados Unidos. Sus elaboraciones doctrinales complejizan mucho más los aspectos políticos derivados de la DSN y presentan diversos aspectos técnico-militares para "combatir" el "problema subversivo" ausentes en las caracterizaciones dominantes sobre DSN. Ello lo reposiciona como un actor central con relativa autonomía para comprender la reformulación del 
proceso represivo, lo que implica hacer a un lado las concepciones instrumentales que aún pretenden explicar el accionar militar. Hubo un proceso de reflexión, crítica y de elaboración propia y conflictiva, con influencias de diferentes latitudes, que buscó establecer los parámetros centrales de una doctrina militar contrasubversiva. Indudablemente, esa relativa autonomía fue, en parte, posibilitada por el alejamiento de su histórica influencia en materia militar durante el gobierno de Carter.

Una lectura crítica de los procesos represivos latinoamericanos requiere seguir avanzando en lecturas que, sin negar el condicionante indiscutible del imperialismo norteamericano, puedan recuperar los condicionantes locales, tanto estructurales como de agencia y acción. Y, aún más, puedan recuperar los "otros" condicionantes transnacionales, las relaciones que los países latinoamericanos establecieron entre sí y con otros países del globo para redefinir sus procesos represivos. $\mathrm{Al}$ respecto queda bastante por entender, tanto en términos históricos como epistemológicos: ¿Cómo se establecieron esos vínculos? ¿Por qué? ¿Cómo se tradujeron las ideas de otras fuerzas armadas a la propia realidad? ¿Deben entenderse como "imposiciones" o más bien como circulación-colaboración en términos ideológicos?

Por último, pudo verse que las tres orientaciones identificadas no son mutuamente excluyentes. De hecho, se encuentran tesis que, por ejemplo, articulan los diagnósticos y las propuestas de acción de "desarrollistas" y "políticos". Queda pendiente para un futuro trabajo analizar cuáles de estas posturas se cristalizaron en las prácticas del Ejército guatemalteco. Una aproximación apresurada permite conjeturar que las tres vertientes tuvieron peso en la elaboración de los planes militares del período. La creación de los polos de desarrollo, el crecimiento exponencial de los organismos de inteligencia y el proceso de "kaibilización" del Ejército al que refiere Manolo Vela (2014), son muestras que estimulan ese trabajo pendiente. 


\section{Anexos}

Tabla 2. Bibliografía citada en las tesis de ascenso de oficiales del Ejército de Guatemala

\begin{tabular}{|c|c|c|}
\hline Tesis & Año & Bibliografía (citada textualmente) \\
\hline \multirow{21}{*}{$\begin{array}{l}\text { Influencia } \\
\text { de los } \\
\text { problemas } \\
\text { socio- } \\
\text { económicos } \\
\text { de } \\
\text { Guatemala } \\
\text { en la guerra } \\
\text { subversiva }\end{array}$} & \multirow{21}{*}{1975} & - When Men Revolt and Why, James Davies \\
\hline & & - Society and Economic growth, Kunkel \\
\hline & & - The Developing Nations, Frank Tachau \\
\hline & & - Rebellion and Authority, Nathan Leites y Charles Wolf \\
\hline & & $\begin{array}{l}\text { - National Liberation: Revolution in the Third World, Norman Miller y Roderick } \\
\text { Aya }\end{array}$ \\
\hline & & - Revolutionary change, Chalmers Johnson \\
\hline & & - Social Aspects of Economic Development, Munt \\
\hline & & - The Urban Guerrilla, Martin Oppenheimer \\
\hline & & $\begin{array}{l}\text { - Introducing Social Change: A Manual for Community Development, Conrad M. } \\
\text { Arensberg y Arthur H. Niehoff }\end{array}$ \\
\hline & & $\begin{array}{l}\text { - The Developing Nations: Poverty and Progress, Irwin Isenberg } \\
\text { - Introducción a la economía, Julio Gómez Padilla }\end{array}$ \\
\hline & & $\begin{array}{l}\text { - The art of Counter-revolutionary war: The Strategy of Counter-Insurgency. John J. } \\
\text { McCuen }\end{array}$ \\
\hline & & $\begin{array}{l}\text { - Philosophy of The Urban Guerrilla: The Revolutionary Writings of Abraham } \\
\text { Guillén, Abraham Guillén }\end{array}$ \\
\hline & & - Anatomy of the Revolution, Crane Brinton \\
\hline & & $\begin{array}{l}\text { - Modernizing Peasant Societies: A comparative Study inn Asia and Africa, Guy } \\
\text { Hunter }\end{array}$ \\
\hline & & - Internal War: Problems and Approaches, Henry Eckstein \\
\hline & & - Economics Development: Principles, Problems and Policies. Bejamin Higgins. \\
\hline & & - Social Change, Wilbert E. Moore. \\
\hline & & - Comunismo en Latinoamérica: El caso de Guatemala, Ronald M. Schneider. \\
\hline & & $\begin{array}{l}\text { - Integración social en Guatemala, Resumen del seminario de Integración } \\
\text { Social Guatemalteca }\end{array}$ \\
\hline & & $\begin{array}{l}\text { - Anuarios estadísticos, 1971-1972 y 1973-1973, Dirección General de } \\
\text { Estadística }\end{array}$ \\
\hline & & - Manual de Guerra Contrasubversiva, Centro de Estudios Militares \\
\hline
\end{tabular}


EN BÚSQUEDA DE UNA DOCTRINA CONTRASUBVERSIVA PROPIA.

LAS TESIS DE ASCENSO DE LOS OFICIALES GUATEMALTECOS, 1975-1985 / 39

\begin{tabular}{|c|c|c|}
\hline Tesis & ño & Bibliografía (citada textualmente) \\
\hline $\begin{array}{l}\text { Importancia } \\
\text { y necesidad } \\
\text { militar de } \\
\text { mantener } \\
\text { oficiales } \\
\text { trabajando } \\
\text { en los } \\
\text { ministerios } \\
\text { de estado }\end{array}$ & 1977 & $\begin{array}{l}\text { - Constitución Política de la República de Guatemala } \\
\text { - Semblanzas (ministros de la Guerra y de la defensa Nacional de } \\
\text { - Auatemala), Coronel de Aviación P.A. Manuel Octavio Zea Carrascosa. } \\
\text { - La politécnica en sus primeros tiempos, Rigoberto Bran Azmitia } \\
\text { - Manual de Organización del Gobierno de la República de Guatemala } \\
\text { - Decretos del Congreso de la República } \\
\text { - Ley del Servicio Civil y Reglamento de los siguientes Ministerios: } \\
\text { Gobernación, Relaciones exteriores, Economía, Trabajo y Previsión Social, } \\
\text { Salud pública y Asistencia Social, Finanzas públicas, Comunicaciones y } \\
\text { Obras públicas, Agricultura y Educación. }\end{array}$ \\
\hline \multirow{7}{*}{$\begin{array}{l}\text { La seguridad } \\
\text { Nacional }\end{array}$} & \multirow{7}{*}{1977} & - Planificacion económica, Harris Seymour \\
\hline & & - Política del poder, Nichoas John Spykman \\
\hline & & $\begin{array}{l}\text { - Política entre las naciones: la lucha por el poder y la paz, Hans J. } \\
\text { Morgenthau }\end{array}$ \\
\hline & & $\begin{array}{l}\text { - La seguridad Nacional, la política y la estrategia, Bra: Mariscal Juarez } \\
\text { Távora }\end{array}$ \\
\hline & & $\begin{array}{l}\text { - Segurança Nacional: antagonismo e vulnerabilidades, General Aurélio Lyra } \\
\text { Tavares }\end{array}$ \\
\hline & & - La moderna Seguridad, Arturo Enrique Barbieri \\
\hline & & $\begin{array}{l}\text { - Libros de seguridad nacional y estrategia de las Escuelas Superiores de los } \\
\text { siguientes países: Argentina, Brasil, Ecuador, Estados Unidos, Guatemala, } \\
\text { Venezuela }\end{array}$ \\
\hline $\begin{array}{l}\text { Proyección } \\
\text { del curso } \\
\text { Kaibil }\end{array}$ & 1979 & $\begin{array}{l}\text { - Material técnico y táctico de la Escuela de Armas del Centro de Estudios } \\
\text { Militares de Guatemala, en sus cursos básico y avanzado de infantería } \\
\text { - Material técnico, táctico y estratégico de la Escuela de las Américas del } \\
\text { Ejército de Estados Unidos, en su curso de comando y estado mayor }\end{array}$ \\
\hline $\begin{array}{l}\text { Necesidad } \\
\text { de } \\
\text { desarrollar } \\
\text { en el } \\
\text { Ejército una } \\
\text { Doctrina } \\
\text { de Guerra } \\
\text { Política. }\end{array}$ & 1979 & $\begin{array}{l}\text { - Fundamentos de filosofía, Victor Afanasiev } \\
\text { - CEM: Lecturas selectas sobre guerra contrasubversiva, Escuela de comando } \\
\text { y Estado Mayor } \\
\text { - Manifiesto del Partido Comunista, Karl Marx y Friedrich Engels. } \\
\text { - Material de instrucción del Curso de Guerra Política, compilado por el } \\
\text { Colegio Político del Ejército Chino, Taipéi, Taiwán } \\
\text { - Tácticas de Lucha Revolucionaria Mundial de los Comunistas Rusos, Wang } \\
\text { Chueh-Yuan } \\
\text { - Sobre la teoría y la práctica de la guerra política, Wang Sheng, General del } \\
\text { Ejército Chino }\end{array}$ \\
\hline
\end{tabular}




\begin{tabular}{|c|c|c|}
\hline Tesis & Año & Bibliografía (citada textualmente) \\
\hline $\begin{array}{l}\text { Comunismo } \\
\text { y subversión }\end{array}$ & 1980 & $\begin{array}{l}\text { - El comunismo y la cuestión social, Número extraordinario, Revista Itsmo } \\
\text { - Sobre la teoría y la práctica de la guerra política, Wang Sheng, General del } \\
\text { Ejército Chino } \\
\text { - Sistema comunista chino de reforma por el trabajo, Cheng Shu-Ping } \\
\text { - El movimiento guerrillero en Guatemala, Adolfo Gilly } \\
\text { - Estudio comparativo de las Tres Principios del Pueblo con otras doctrinas, } \\
\text { Wang Sheng, General del Ejército Chino } \\
\text { - Renuncia al comunismo, C.M. Pellecer } \\
\text { - Acciones criminales de los comunistas chinos en su persecución religiosa, Shen } \\
\text { Ping-Wen } \\
\text { - Acerca de Teng Hsiao-Ping, Wag Hsuan } \\
\text { - La opinión pública condena la violencia, Publicaciones de la Secretaría de } \\
\text { RRPP de la presidencia de Guatemala } \\
\text { - La Rusia soviética en China, Chiang Kai-Shek } \\
\text { - El pensamiento económico del siglo XX, Colegio político Taipéi, Taiwán, } \\
\text { República de China } \\
\text { - Estudio de la táctica comunista y las medidas contraofensivas, Colegio } \\
\text { político Taipéi, Taiwán, República de China } \\
\text { - El pensamiento social del siglo XX, Colegio político Taipéi, Taiwán, } \\
\text { República de China } \\
\text { - Cuadros sinópticos de las doctrinas comunistas chinas, Colegio político } \\
\text { Taipéi, Taiwán, República de China } \\
\text { - El pensamiento político del siglo XX, Colegio político Taipéi, Taiwán, } \\
\text { - República de China } \\
\text { - La subversión, Fuerzas Armadas del Uruguay. } \\
\text { - Organización de fachada del comunismo internacional, Jorge Méndez } \\
\text { subversiva, Clave A-51 }\end{array}$ \\
\hline $\begin{array}{l}\text { La guerra } \\
\text { de guerrillas } \\
\text { en la lucha } \\
\text { subversiva }\end{array}$ & 1980 & - Sin bibliografía \\
\hline
\end{tabular}




\begin{tabular}{|c|c|c|}
\hline Tes & Año & Bibliografía (citada textualmente) \\
\hline $\begin{array}{l}\text { Cómo } \\
\text { erradicar la } \\
\text { subversión } \\
\text { en } \\
\text { Chimalte- } \\
\text { nango }\end{array}$ & 1981 & 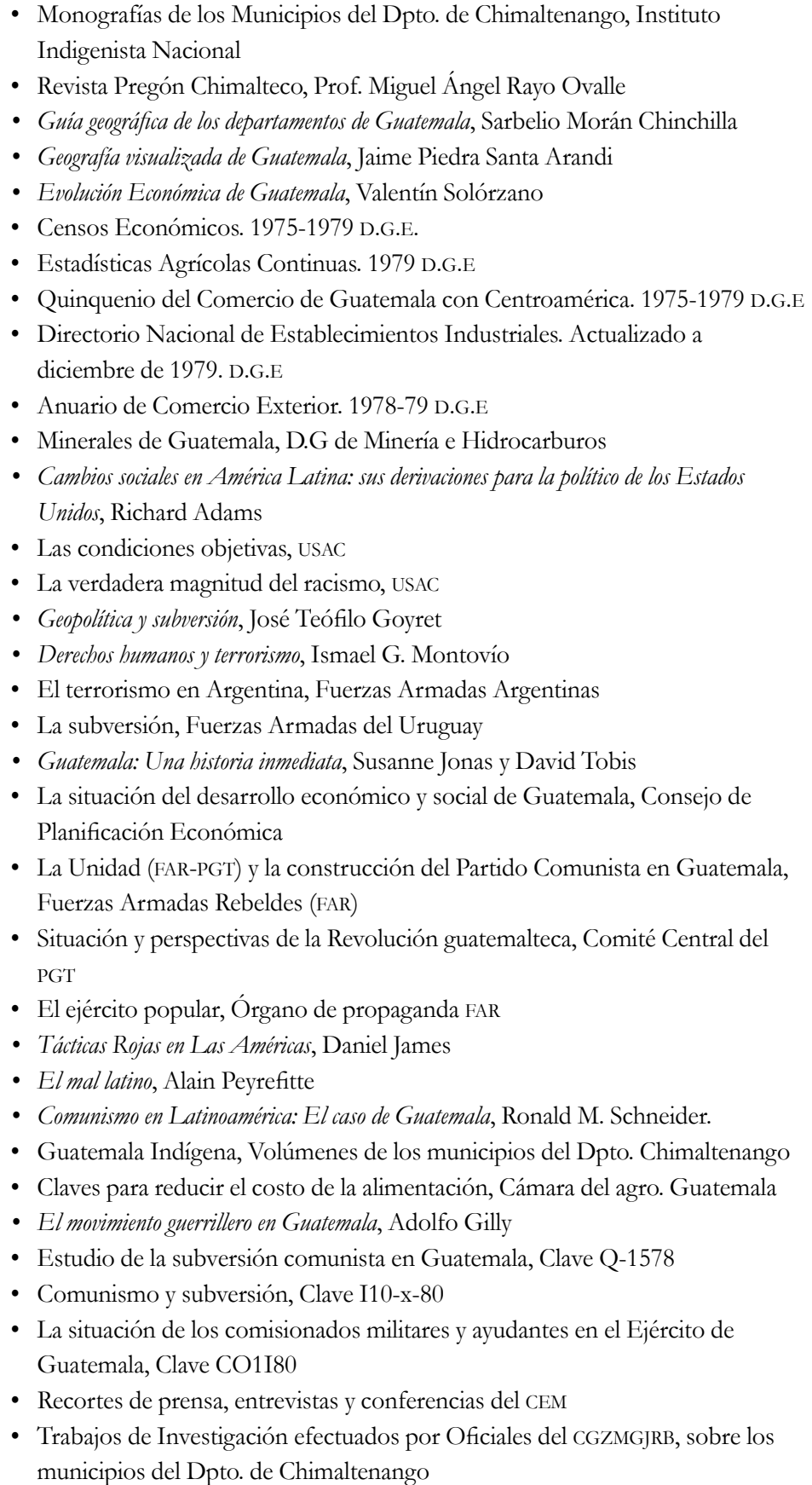 \\
\hline
\end{tabular}




\begin{tabular}{|c|c|c|}
\hline Tesis & Año & Bibliografía (citada textualmente) \\
\hline $\begin{array}{l}\text { Estudio de } \\
\text { la doctrina } \\
\text { de contra- } \\
\text { insurgencia } \\
\text { 1960-1982 }\end{array}$ & 1982 & $\begin{array}{l}\text { - Manual de guerra contrasubversiva, CEM } \\
\text { - Directivas emanadas por el EMGE } \\
\text { - Tesis de ascenso relacionadas con el problema } \\
\text { - "La coyuntura", Autocrítica del movimiento comunista y subversivo en } \\
\text { - Guatemala } \\
\text { - Documento COTRAM, Comisión de Trabajo de masas (Subversivas) } \\
\text { - Documentos de planificación económica } \\
\text { - Historia del comunismo en Guatemala } \\
\text { - La formación del Ejército popular (EMGE) }\end{array}$ \\
\hline $\begin{array}{l}\text { Análisis de } \\
\text { táctica y } \\
\text { estrategia } \\
\text { empleada } \\
\text { por el } \\
\text { ejército de } \\
\text { Guatemala, } \\
\text { en la lucha } \\
\text { contra- } \\
\text { subversiva } \\
\text { de } 1962 \text { a la } \\
\text { actualidad }\end{array}$ & 1985 & $\begin{array}{l}\text { - Estudio de la doctrina contrasubversiva } \\
\text { - Las causas de la subversión marxista, Volumen XI N } 1 \text { 1983, Colegio } \\
\text { - Enteramericano de Defensa } \\
\text { - Estudio de la subversión comunista en Guatemala 1944-1971 } \\
\text { - Resumen de inteligencia 002-1983 EMDN } \\
\text { - Informe periódico de Inteligencia 002-1982 EMDN } \\
\text { - Apreciación de Inteligencia de la situación subversiva, agosto1980 } \\
\text { - Resumen de inteligencia 1981 } \\
\text { - Revista Militar CEM nro. 24, } 1981 \\
\text { - Revista Militar CEM nro. 25, } 1982 \\
\text { - Revista Militar CEM nro. 28, } 1983 \\
\text { - Directivas del EMDN que norman entrenamiento y operaciones } \\
\text { contrasubversivas de 1960-1985 } \\
\text { - Plan de Campaña "Victoria 82" } \\
\text { - Plan de Campaña "Firmeza 83" } \\
\text { - Plan de Campaña "Firmeza 83-I" } \\
\text { - Plan de Campaña "Reencuentro Institucional } 84 " \\
\text { - Plan de Campaña "Estabilidad Nacional } 85 " \\
\text { - Documentos incautados al enemigo: Situación y perspectivas del } \\
\text { - Movimiento Revolucionario Guatemalteco 1967 } \\
\text { - La ideología y la política } \\
\text { - Materias de formación política EGP } 1980 \\
\text { - Nuestra concepción militar } \\
\text { - Clandestinidad y métodos de seguridad } \\
\text { - Nuestra organización es el EGP } \\
\text { - ¿Cómo vamos a tomar el poder? 1979 } \\
\text { - Once años de lucha ORPA }\end{array}$ \\
\hline
\end{tabular}




\section{Referencias}

Aguilera Peralta, G. (2012). El pensamiento militar guatemalteco. En V. Álvarez Aragón, C. Figueroa Ibarra, A. Taracena Arriola, S. Tischler Visquerra, \& E. Urrutia (Eds.), Guatemala: historia reciente (1954-1996). Proceso político y antagonismo social. Tomo I (pp. 365- 407). Guatemala: FLACSO.

Anderson, S., \& Anderson, J. L. (1986). Inside the League. The shocking exposé of how terrorist, Nazis and Latin American death squads have infiltrated the world anti-communist League. Nueva York: Dodd, Mead \& Company.

Armony, A. (1999). La Argentina, los Estados Unidos y la cruzada anticomunista en América Central, 1977-1984. Bernal: Universidad Nacional de Quilmes.

Barros, A., \& Coelho, E. (1981). Military intervention and withdrawal in South America. International Political Science Review, 2(3), 341-349.

Bourdieu, P. (2017). Las condiciones sociales de la circulación internacional de las ideas. En Intelectuales, política y poder (pp. 159-170). Buenos Aires: Eudeba.

Buchrucker, C. (1994). Las formas autoritarias del nacionalismo y el conservadurismo latinoamericanos. Ciclos, IV, (1941), 189-212.

Calloni, S. (2001). Operación Cóndor. Pacto criminal. México: Ediciones Continente.

Calvo, R. (1979). La doctrina militar de la seguridad nacional. Autoritarismo político y neoliberalismo económico en el Cono Sur. Caracas: Universidad Católica Andrés Bello.

Chateau, J. (1983). Seguridad Nacional y Guerra antisubversiva. Santiago de Chile: FLACSO. Recuperado de http:/ / flacsochile.org/biblioteca/pub/ memoria/1983/001028.pdf

Comblin, J. (1976). La Seguridad Nacional. Revista Mensaje, (247), 96-104.

Comblin, J. (1978). El poder militar en América Latina. Salamanca: Ediciones Sígueme.

Comblin, J. (1979). La Doctrina de la Seguridad Nacional. En Estudios Nº, Vicaría de la Solidaridad, Dos Ensayos sobre Seguridad Nacional (pp. 9-191). Santiago de Chile: Arzobispado de Santiago, Vicaría de la Solidaridad. Drouin, M. (2017). Permitir que solamente la buena planta crezca. La guerra contrasubversiva guatemalteca y sus raíces francesas. En R. García Ferreira \& A. Taracena Arriola (Comps.), La guerra fría y el anticomunismo en Centroamérica (xx-xx). Guatemala: FLACSO. 
Figueroa Ibarra, C. (2012). Genocidio y terrorismo de Estado en Guatemala (1954-1996): una interpretación. En V. Álvarez Aragón, C. Figueroa Ibarra, A. Taracena Arriola, S. Tischler Visquerra, \& E. Urrutia, Guatemala: Historia reciente (1954-1996), Tomo I Proceso político y antagonismo social (pp. 169-198). Guatemala: FLACSO.

García, P. (2005). El genocidio de Guatemala a la luz de la sociología militar. Madrid: Sepha.

Gazzera, C. (26 de marzo de 2006). Siete postales del horror cultural. La Voz online. Recuperado de http://archivo.lavoz.com.ar/2006/0326/ UM/nota401058_1.htm

Gill, L. (2004). The School of the Americas. Military training and political violence in the Americas. Durham, Londres: Duke University Press.

Leal Buitrago, F. (2002). La seguridad nacional a la deriva: del Frente Nacional a la posguerra fría. Colombia y Ecuador: Alfaomega, CESO, FLACSO.

Leal Buitrago, F. (2003). La doctrina de Seguridad Nacional: Materialización de la Guerra Fría en América Latina. Revista de Estudios Sociales, (15), 74-87. https://doi.org/10.7440/res15.2003.05

López, E. (1985). Doctrinas militares en Argentina: 1932-1980. En C. Moneta, E. López, \& A. Romero. La reforma militar (pp. 103-143). Buenos Aires: Legasa.

López, E. (1987). Seguridad Nacionaly Sedición Militar. Buenos Aires: Legasa. López, E. (1989). Doctrina de la Seguridad nacional. En T. S. Di Tella (Supervisión). Diccionario de ciencias sociales y politicas (pp. ). Buenos Aires: Emecé.

López, F. (2016). The feathers of condor: Transnational state terrorism, exiles and civilian anticommunism in South America. Reino Unido: Cambridge.

Maira, L. (1990). El Estado de la Seguridad Nacional en América Latina. En P. González Casanova (Coord.), ElEstado en América Latina. Teoría y práctica. Buenos Aires: Siglo Veintiuno Editores, Universidad de las Naciones Unidos (UNU).

Martorell, F. (1999). Operación Cóndor, el vuelo de la muerte: la coordinación represiva en el Cono Sur. Santiago de Chile: LOM Ediciones.

Mazzei, D. (2002). La misión militar francesa en la escuela superior de Guerra y los orígenes de la Guerra Sucia, 1957-1962. Revista de Ciencias Sociales, (13), 105-137.

McSherry, P. (2009). Los Estados depredadores: la operación Cóndor y la guerra encubierta en América Latina. Santiago de Chile: LOM Ediciones. 
Methol Ferré, A. (1979). Sobre la actual ideología de la Seguridad Nacional. En Estudios $N^{\circ}$ 6, Vicaría de la Solidaridad. Dos Ensayos sobre Seguridad Nacional. Santiago de Chile: Arzobispado de Santiago, Vicaría de la Solidaridad.

Mundim, L. F. C. (2015). Juarez Távora e a organização do estado Brasileiro: racionalismo administrativo, sindicalismo-cooperativista e cristianismo social no pensamento militar pré-golpe de 1964. Antíteses, 8(16), 327352. https://doi.org/10.5433/1984-3356.2015v8n16p327

Nabuco de Araujo, R. (2012). L'art français de la guerre. Transferts de la doctrine de la guerre révolutionnaire au Brésil (1958-1974). Cahiers des Amériques latines, (70), 39-58. https://doi.org/10.4000/cal.2339

Nabuco de Araujo, R. (2016). La coopération entre les services de renseignement français et brésilien (1964-1975) : contre-révolution, anticommunisme et répression. Nuevo Mundo Mundos Nuevos, 1-14. https:// doi.org/10.4000/nuevomundo.68873

Nina, A. (1979). La Doctrina de Seguridad Nacional y la integración latinoamericana. Nueva Sociedad, (27), 33-50.

Padrós, E. S., \& Slatman, M. (2012). Dossier: coordinaciones represivas en el Cono Sur de América Latina (1964-1991). Taller (Segunda Época), Revista de Sociedad, Cultura y Politica, 1(1). Recuperado de https://taller.historiaoralargentina.org/

Périès, G. (1999). De l'action militaire à l'action politique. Impulsion, codification et application de la doctrine de la "guerre révolutionnaire" au sein de l'Armée française (1944-1960). París: Université de Paris I.

Périès, G. (2009). De Argelia a la Argentina: estudio comparativo sobre la internacionalización de las doctrinas militares francesas en la lucha anti-subversiva. Enfoque institucional y discursivo. En I. Izaguirre (Comp.), Lucha de clases, guerra civily genocidio en la Argentina, 1973-1983: Antecedentes, desarrollo, complicidades (pp. 391-421). Buenos Aires: Eudeba.

Pion-Berlin, D. (1989). Latin American National Security Doctrines: Hard and Softline Themes. Armed Forces \& Society, 15(3), 411-429. https:/ / doi.org/10.1177/0095327X8901500305

Ranalletti, M. (2018). Réexaminer la question de l' implantation de la « doctrine de la guerre révolutionnaire » en Argentine. Histoire Politique, 34. Recuperado de https:/ /www.histoire-politique.fr

Robin, M.-M. (2014). Escuadrones de la muerte. La escuela francesa. La Plata: De la Campana. 


\section{6 / LaURa Yanina SaLa}

Rosada Granados, H. (2011). Soldados en elpoder: proyecto militar en Guatemala (1944 - 1990). Thela: Guatemala.

Rostica, J. (2016). La política exterior de la dictadura cívico-militar argentina hacia Guatemala (1976-1983). Estudios, (36), 95-119.

Rostica, J. (2018). La transnacionalización de ideas: la escuela contrasubversiva de Argentina a Guatemala. Diálogos, 149-176.

Sala, L. (2017). La encrucijada militar: cambios políticos y Fuerzas Armadas en Guatemala, 1982-1996. Una aproximación socio-bistórica a las transformaciones en la institución militar guatemalteca. Tesis de Maestría en Estudios Latinoamericanos, Universidad Nacional de San Martín.

Sala, L. (2018a). Enemigos, población y guerra psicológica. Los “saberes contrasubversivos" argentinos y su (re)apropiación por los militares guatemaltecos. Revista Diálogos, 19(2), 140-169. Recuperado de https:/ / revistas.ucr.ac.cr/index.php/dialogos/article/view/31200/33297

Sala, L. (2018b). Los militares estratégicos y la reformulación del pensamiento militar. Guatemala 1978-1986. Latinoamerica. Revista de Estudios Latinoamericanos, (67), 203-238. https://doi.org/10.22201/ cialc. $24486914 \mathrm{e} .2018 .67 .57034$

Schirmer, J. (1999). Intimidades del proyecto politico de los militares en Guatemala. Guatemala: FLACSO.

Shirley, S. L. (1997). The Impact of US Security Assistance in Guatemala. Austin: University of Texas.

Tapia Valdés, J. (1980). El Terrorismo de Estado. La Doctrina de la Seguridad Nacional en el Cono Sur. México D. F.: Nueva Imagen.

Thomas, M. (2013). La gran confrontación: el segundo ciclo revolucionario 1972-1983. En V. Álvarez Aragón, C. Figueroa Ibarra, A. Taracena Arriola, S. Tischler Visquerra, \& E. Urrutia (Eds.), Guatemala: historia reciente 1954-1996. La dimensión revolucionaria. Tomo II (pp. 121-198). Guatemala: FLACSO.

Vela, M. (2014). Los pelotones de la muerte. La construcción de los perpetradores del genocidio guatemalteco. México D. F.: El Colegio de México.

Velásquez Rivera, É. D. J. (2002). Historia de la Doctrina de la Seguridad Nacional. Convergencia, 27, 11-39. 


\section{Fuentes}

Tesis de ascenso de oficiales del Ejército de Guatemala. Biblioteca del Estado Mayor de la Defensa Nacional:

A51. (1975). Influencia de los problemas socio-económicos de Guatemala en la guerra subversiva de 1975. (Tesis de ascenso). CEM, Guatemala.

CA3097. (1977). Importancia y necesidad militar de mantener oficiales trabajando en los ministerios de estado. (Tesis de ascenso). CEM, Guatemala.

CA2597. (1979). Seguridad Nacional. (Tesis de ascenso). CEM, Guatemala.

I01X79. (1979). Necesidad de desarrollar en el Ejército una Doctrina de Guerra Política. (Tesis de ascenso). CEM, Guatemala.

108X79. (1979). Proyecciones del curso kaibil en el ejército de Guatemala. (Tesis de ascenso). CEM, Guatemala.

I09X80. (1980). La guerra de guerrillas en la lucha subversiva. (Tesis de ascenso). CEM, Guatemala.

I10X80. (1980). Comunismo y subversión. (Tesis de ascenso). CEM, Guatemala.

I21X81. (1981). Cómo erradicar la subversión en Chimaltenango. (Tesis de ascenso). CEM, Guatemala.

S/d- (1982). Estudio de la doctrina de contrainsurgencia 1960-1982. (Tesis de ascenso). CEM, Guatemala.

I37X85. (1985). Análisis de táctica y estrategia empleada por el ejército de Guatemala, en la lucha contrasubversiva de 1962 a la actualidad. (Tesis de ascenso). CEM, Guatemala.

\section{Otras fuentes}

Ministerio de RREE y Culto. (1980). Memorias. Año 1980. Buenos Aires: MrEC. Ministerio de RREE y Culto. (1981). Memorias. Año 1981. Buenos Aires: MREC. Reglamento de Ascensos del Ejército de Guatemala, Acuerdo Gubernativo 3-80. 